Prog Nucl Magn Reson Spectrosc. 2011 October ; 59(3): 197-212. doi:10.1016/j.pnmrs.2010.11.002.

\title{
In-Cell NMR Spectroscopy
}

\author{
Andres Y. Maldonado, David S. Burz, and Alexander Shekhtman \\ Department of Chemistry, State University of New York at Albany, Albany, NY 12222
}

\author{
Keywords \\ in-cell NMR; structural biology; proteomics; protein-protein interactions; small molecule library \\ screening
}

\section{Introduction}

Interactions between biological macromolecules give rise to and regulate biological activity. This activity is manifest through structural dynamics and changes in the macromolecular structures that comprise these interactions [1-3]. Until recently, mostly in vitro techniques have been used to study macromolecular interactions that govern biological processes under conditions remote from those existing in the cell [4]. With the advent of in-cell Nuclear Magnetic Resonance (NMR) spectroscopy [4], these processes can now be studied within a cellular environment.

In-cell NMR spectroscopy provides atomic level resolution of molecular structures under physiological conditions. NMR-active nuclei in biological macromolecules are extremely sensitive to changes in the chemical environment resulting from specific and non-specific binding interactions with ions, small effector ligands and macromolecules as well as from changes due to biochemical modifications. These interactions alter molecular surfaces and may result in tertiary and quaternary conformational changes, all of which are reflected by changes in the chemical shifts of these nuclei. Thus, by performing NMR spectroscopy on living cells, we can begin to understand the structural underpinning of biological activity.

As the field of in-cell NMR spectroscopy has progressed, the severity of early concerns regarding the validity of in-cell NMR for studying biological macromolecules has abated. Chemical shift differences between the resonance peaks of proteins measured in-cell versus those measured in vitro are small, reflecting the effect of the intracellular environment on the protein structure. Potential pitfalls in the technique are the need for abnormally high, non-physiological concentrations of the labeled target because of low signal intensity, the effects of molecular crowding inherent to the cytosol, the relevance of studying prokaryotic proteins in a eukaryotic intracellular milieux, the viability of cells during data acquisition and the ability to expand in-cell methodology to eukaryotic cells. These potential problems have proven to be more tractable than expected $[15,48]$. The results have reaffirmed the

(C) 2010 Elsevier B.V. All rights reserved.

Corresponding Author: Alexander Shekhtman, Department of Chemistry, State University of New York at Albany, Albany, NY 12222, ashekhta@albany.edu, tel: 1-(518)442-4163.

All authors contributed equally to this work.

Publisher's Disclaimer: This is a PDF file of an unedited manuscript that has been accepted for publication. As a service to our customers we are providing this early version of the manuscript. The manuscript will undergo copyediting, typesetting, and review of the resulting proof before it is published in its final citable form. Please note that during the production process errors may be discovered which could affect the content, and all legal disclaimers that apply to the journal pertain. 
power of in-cell NMR spectroscopy to measure changes in structure, resulting from posttranslational biochemical modification, interactions with other biological molecules and/or allosteric changes resulting from binding interactions under physiological or near physiological conditions and in determining three-dimensional (3D) structures de novo.

\section{Methodologies}

\subsection{Target labeling}

To use NMR spectroscopy to study biological macromolecules in living cells the labeled targets must be easily distinguished from all other species present. Specific isotopic labeling schemes are employed to detect and resolve in-cell NMR protein resonance peaks and to yield the lowest background signals.

2.1.1 Backbone group probes-The most commonly used scheme employs ${ }^{15} \mathrm{NH}_{4} \mathrm{Cl}$ as the sole nitrogen source to incorporate NMR-active ${ }^{15} \mathrm{~N}$ nuclei into the peptide backbone of proteins over-expressed in bacterial cells. This uniform $\left[U_{-}{ }^{15} \mathrm{~N}\right]$ labeling strategy results in diminished background resonance peaks because bacterial growth is significantly reduced during protein over-expression. The protein resonance peaks of the resulting ${ }^{1} \mathrm{H}\left\{{ }^{15} \mathrm{~N}\right\}$ HSQC [5] (heteronuclear single quantum coherence) spectra are adequately resolved provided that the protein is expressed to a sufficiently high concentration within the cell.

Another backbone labeling scheme uses auxotrophic bacterial strains [6,7] to incorporate high levels of amino acids that have been specifically enriched with ${ }^{15} \mathrm{~N}$. Arginine, histidine and lysine are ideal for this type of labeling [6] since these amino acids lie at the end of their respective biosynthetic pathways. Labeled amino acids are chosen so as to comprise a substantial number of the total residues in the protein being expressed, since only those residues will contribute to the NMR spectrum. As a result of the less extensive labeling, the resulting in-cell spectrum will necessarily exhibit lower resolution than a spectrum obtained for a uniformly labeled target, but will be essentially devoid of background signals. Other amino acids can be used with the caveat that there will be an unavoidably larger background signal due to the presence of multiple metabolic products.

Proteins may also be uniformly labeled in bacteria by using ${ }^{13} \mathrm{C}$ as the sole carbon source during bacterial over-expression. Uniform $\left[U_{-}{ }^{13} \mathrm{C}\right]$ labeling results in a high background due to metabolic reactions and the natural abundance of ${ }^{13} \mathrm{C}(1.1 \%)$, and is generally not used in this capacity. Selective ${ }^{13} \mathrm{C}$-isotopic labeling of constituent amino acids offers a better opportunity for enhancing the signal and minimizing the background. This isotope is best suited for labeling amino acid side chain residues, particularly methyl and methylene groups.

2.1.2 Methyl group probes-To produce narrow resonance lines for in-cell NMR, the protein of interest must tumble rapidly inside the cell. The rate of tumbling decreases as the size of the molecule increases, limiting in-cell NMR to the study of small molecules. Serber et al. [8] extended in-cell NMR spectroscopy to the study of larger molecules by selectively incorporating isotopically labeled methyl groups into protein over-expressed in bacteria.

Methyl groups contain three protons coupled to carbon and generate an NMR spectrum with three times the sensitivity obtained from a single amide proton. Due to rapid local motions, methyl protons also have longer transverse relaxation times $\left(\mathrm{T}_{2}\right)$ than amide protons, which further increases the effective sensitivity of the NMR signal. In addition, amide protons chemically exchange with water resulting in a loss of signal due to exchange broadening, whereas methyl group protons do not. Therefore, methyl groups provide probes that are more sensitive than amide groups for in-cell NMR studies. 
Serber et al. [8] tried different labeling schemes to determine which yielded the greatest resolution and lowest background. When ${ }^{13} \mathrm{C}$-glucose was used to uniformly label calmodulin in E. coli, the ${ }^{1} \mathrm{H}\left\{{ }^{13} \mathrm{C}\right\}$-HSQC spectrum of these cells has a high background, which precluded identifying most of the methyl group proton resonances. When ${ }^{13} \mathrm{C}$ pyruvate, a precursor for the biosynthesis of amino acids side chains, was used as the sole carbon source [9] to label over-expressed calmodulin in $\mathrm{D}_{2} \mathrm{O}$-minimal medium, the overall number of peaks in the spectrum was reduced relative to those obtained by using full labeling since only the amino acids that required pyruvate as a precursor incorporated the ${ }^{13} \mathrm{C}$ labeling. Many protein resonance peaks were observed, but assigning specific resonances was hampered by substantial overlap with broad background peaks.

Peak resolution was improved and background reduced by using a single labeled amino acid. $\left({ }^{13} \mathrm{C}\right.$-methyl $)$-methionine was used to label calmodulin overexpressed in minimal medium. The resulting ${ }^{1} \mathrm{H}\left\{{ }^{13} \mathrm{C}\right\}$-HSQC spectrum is dominated by free methionine and welldefined calmodulin methionine resonances. Free $\left({ }^{13} \mathrm{C}\right.$-methyl $)$-methionine was removed from the in-cell sample by washing the cells prior to NMR spectroscopy to yield a further reduction in background peaks. When $\left({ }^{13} \mathrm{C}\right.$-methyl)-alanine was used to label NmerA, the resulting spectrum has a higher background than observed using $\left({ }^{13} \mathrm{C}\right.$-methyl $)$-methionine, as well as free alanine and NmerA alanine resonances. By using M9 medium supplemented with unlabeled amino acids and nucleosides [10], the background was reduced even further because of minimal label scrambling. Thus, selective isotopic labeling of methyl groups provides a viable probe to study large molecular complexes using in-cell NMR spectroscopy.

2.1.3 Fluorine probes-The study of ${ }^{15} \mathrm{~N}$ labeled globular proteins by in-cell NMR is hampered by the high viscosity and weak interactions that occur in the cytoplasm, which result in a reduction in signal intensity. Wang et al. [11] demonstrated an ${ }^{19} \mathrm{~F}$ NMR labeling strategy that is applicable to the in-cell study of both globular and disordered proteins. ${ }^{19} \mathrm{~F}$ labeling is very attractive for in-cell NMR studies. The gyromagnetic ratio and natural abundance of ${ }^{19} \mathrm{~F}$ is very close to that of ${ }^{1} \mathrm{H}$ making ${ }^{19} \mathrm{~F}$ almost as sensitive as protons and the ${ }^{19} \mathrm{~F}$ chemical shift range is at least ten times larger than that of protons, which confers greater resolution. Naturally occurring proteins do not contain fluorine so that ${ }^{19} \mathrm{~F}$ labeled amino acids introduced during bacterial over-expression will result in a very low NMR background signal. Acquisition times to collect $1 \mathrm{D}^{19} \mathrm{~F}$ spectra are very short compared to those of 2D-HSQC experiments, and therefore proteins may be studied near physiological concentrations.

Wang et al. [11] examined one disordered and five globular proteins labeled with ${ }^{19} \mathrm{~F}$, ranging in size from 7 to $100 \mathrm{kDa}$ : $\alpha$-synuclein $(\alpha-\mathrm{SYN})$, ubiquitin (Ub), chymotrypsin inhibitor 2 (CI2), calmodulin, green fluorescence protein (GFP) and hisidinol dehydrogenase. Two fluorinated amino acid analogs, 3-fluro-tyrosine (3FY), and trifluoromethyl-L-phenylalanine $(\mathrm{tfmF})$ were separately incorporated into each protein. $3 \mathrm{FY}$ labeling was accomplished by expressing the protein in minimal media containing $3 \mathrm{FY}$, phenylalanine, tryptophan, and $N$-(phosphomonethyl) glycine. The tfmF labeling utilized an orthogonal tRNA synthase system to replace residues with tfmF [12].

${ }^{19} \mathrm{~F}$ spectra for in-cell, supernatant and lysate samples were acquired for each protein to determine quality and dispersion. All globular proteins examined yielded strong welldispersed ${ }^{19} \mathrm{~F}$ peaks. Cell leakage was checked by comparing the supernatant spectrum with the in-cell spectrum for ${ }^{19} \mathrm{~F}$. The results showed that ${ }^{19} \mathrm{~F}$ in-cell NMR is an easy way of monitoring protein leakage. Only the globular protein CI2 showed signs of leakage. The viability of using ${ }^{19} \mathrm{~F}$ NMR for in-cell analyses of disordered proteins was also demonstrated by using $\alpha-\mathrm{SYN}$ as a model disordered protein. 


\subsection{In-cell NMR samples}

Proper preparation of samples for in-cell NMR spectroscopy is critical for acquiring high quality in-cell spectra. The concentration of labeled nuclei must be high enough to provide well-resolved resonances for unambiguous identification. Several methods have been employed to introduce target proteins into both prokaryotic and eukaryotic cells. These methods have their advantages and disadvantages, but all have proven effective in facilitating the acquisition of reproducible in-cell NMR spectra.

2.2.1 Over-expression-The most popular and convenient method for producing labeled targets for in-cell NMR spectroscopy involves over-expressing protein using an inducible plasmid in bacterial cells. The concentration of over-expressed protein can be controlled by using tightly regulated promoters whose level of transcription is proportional to the concentration of the inducing molecule (eg. the arabinose $\mathrm{P}_{\mathrm{BAD}}$ [13] and rhamnose $\mathrm{P}_{\mathrm{RHA}}$ [14] ). Other methods for controlling the levels of intracellular concentration of overexpressed labeled protein include varying the induction time and using plasmids with greater or lesser copy number. Polyacrylamide gel electrophoresis (PAGE) or Western blot analyses are typically employed to determine the final intracellular concentration of over-expressed target proteins. Eukaryotic cells have been used to produce protein, but uniform high level isotopic labeling in these cells is fraught with difficulties, rendering a homogeneous sample difficult to obtain. Over-expression has the advantage of creating the target protein within the cellular milieu in which it will be studied; no exogenous translocations or extracellular manipulations are involved, making it the simplest and most straightforward method for generating samples for use in-cell NMR spectroscopy.

2.2.2 Microinjection-Microinjecting labeled protein into cells has advantages over endogenously over-expressing labeled protein: the concentration of labeled protein can be accurately and reproducibly controlled and the background generated by over-expression is eliminated, allowing for in-cell sample preparations with an effectively zero background. The only significant contribution to background arises from the natural abundance of ${ }^{13} \mathrm{C}$ (1.1\%). The primary disadvantages are that only large, easily manipulated cells, such as $X$. laevis oocytes, are amenable to this procedure, the process is tedious and there is an inherent variability in the oocytes.

Selenko et al. [15] used a robotic microinjection device to administer precise quantities of streptococcal protein G B1 domain (GB1) [16] into X. laevis oocytes [17]. GB1 was uniformly $\left[U_{-}{ }^{15} \mathrm{~N}\right]$ labeled in and purified from E. coli. As a prelude to in-cell NMR spectroscopy, the initial NMR experiments were performed using $X$. laevis egg extracts as a model system to mimic the intracellular milieu. Results showed that intracellular components do not appear to affect the folded state of the protein domain and revealed no intracellular binding partners. The spectrum of ${ }^{15} \mathrm{~N}-\mathrm{GB} 1$ obtained in extracts is virtually identical to that obtained in vitro using purified protein over the concentration range examined.

Next, X. laevis oocytes were injected with purified ${ }^{15} \mathrm{~N}-\mathrm{GB} 1$ to intracellular concentrations ranging from 50-500 $\mu \mathrm{M}$. Intracellular ${ }^{15} \mathrm{~N}-\mathrm{GB} 1$ produced high quality $2 \mathrm{D}$ spectra, generally matching peaks seen in spectra acquired in vitro by using purified protein (Fig. 1). Some peaks display a distorted, split profile that was attributed to different chemical shifts arising from different intracellular environments. This observation was substantiated by dissecting single oocyte cell nuclei and demonstrating that GB1 was found in both the cytoplasm and nucleus.

There were no discernable differences in the quality of the resulting NMR spectra acquired under identical conditions of temperature and data acquisition time, however, oocytes that 
had been automatically injected were found to be more viable than those that were manually injected. Control experiments showed no leakage of labeled protein from the cells. This work demonstrated the feasibility of performing in-cell NMR spectroscopy in X. laevis oocytes and the use of Xenopus egg extracts to optimize conditions for high-resolution NMR spectroscopy in eukaryotic cells.

Bodart et al. [18] studied the neuronal protein, tau, inside X. laevis oocytes, an environment in which it is not normally found [19]. Tau interacts with the microtubular network present in oocytes, thus providing an opportunity to perform in-cell NMR spectroscopy on a target protein in the bound state. Tau was uniformly $\left[U_{-}{ }^{15} \mathrm{~N}\right]$ labeled in and purified from bacteria $[20,21]$. The protein was microinjected into $X$. laevis oocytes to a final concentration of $\sim 5$ $\mu \mathrm{M}$, which is close to physiological levels. The resulting ${ }^{1} \mathrm{H}\left\{{ }^{15} \mathrm{~N}\right\}-\mathrm{HSQC}$ spectrum was similar to that of a purified sample obtained in vitro [22], but the cross peaks were broadened and many, attributed to free tau, were missing. After mechanically lysing the cells and re-acquiring the spectrum, the peak intensity increased but still lacked the peaks associated with free tau. Instead the spectrum resembled that of tau bound to tubulin [22]. Therefore, the peak broadening, which leads to lower resolution spectra, is likely due to tau interacting with tubulin and possibly other proteins present in the oocyte.

Bodart et al. [18] examined methods used to optimize the reproducibility of spectra acquired from different in-cell preparations and by varying just one acquisition parameter. They concluded that while the overall spectral profile is improved by injecting the same solution into the same injection site on the oocyte and selecting oocytes in a qualitatively reproducible manner, the physiological state of the individual oocytes likely contributes to variations in signal strength, and therefore collecting a series of meaningful spectra on different samples will not be straightforward.

The results show that tau can be studied in cells at an intracellular concentration of $\sim 5 \mu \mathrm{M}$, extending the lower limit of concentration that can be successfully studied by using in-cell NMR spectroscopy, although many of the resonances are broadened because of proteinprotein interactions, yielding low resolution spectra.

2.2.3 Cell penetrating peptides-Inomata et al. [23] utilized a previously untested procedure for introducing isotopically labeled proteins into eukaryotic cells by using cell penetrating peptides (CPP) [24-26] to transduce human HeLa cells. Uniformly $\left[U_{-}{ }^{15} \mathrm{~N}\right]$ labeled protein was covalently tagged or conjugated with a cell-penetrating peptide derived from the Tat protein of HIV-1 (CPP Tat) [27], and incubated with human HeLa cells and pyrenebutyrate. Pyrenebutyrate mediates the translocation of CPP-tagged proteins into the cytosol [28].

Experiments were performed using a ubiquitin (Ub-3A) that was mutated at three sites (L8A, I44A, V70A) [29] to preclude binding with ubiquitin-interacting proteins (UIPs). The $\left[U-{ }^{15} \mathrm{~N}\right]$ labeled Ub-3A contained a C-terminal CPP fusion (Ub-3A-CPP $\left.{ }_{\text {Tat }}\right)$. Following transduction, a well-resolved ${ }^{1} \mathrm{H}\left\{{ }^{15} \mathrm{~N}\right\}$-HSQC spectrum was observed. The in-cell spectrum lacked the cross peak corresponding to the $\mathrm{C}$-terminal $\mathrm{CPP}$ residue and showed an intense signal corresponding to the C-terminal glycine (G76) of Ub-3A. Control experiments showed that Ub-3A-CPP ${ }_{\text {Tat }}$ was cleaved between $\mathrm{G} 76$ and D77, presumably by endogenous ubiquitin-specific C-terminal proteases (DUBs) [30] to yield free Ub-3A (Fig 2).

Cleavage of the peptide tag is not only desirable, but necessary. It is well known that CPPs aggregate with many cytosolic components, including the inner plasma membrane [26]. Proteins bound to CPPs also form aggregates, producing broad, overlapping signals in NMR spectra. Experiments performed using an uncleavable CPP demonstrated that cleavage is 
essential for a well-resolved spectrum of the target protein. In addition, cleaved proteins exhibited a uniform intracellular distribution, whereas, CPP-tagged proteins are heterogeneously dispersed throughout the cytosol. CPP cleavage is therefore essential for uniform protein distribution.

The concentration of transduced Ub-3A-CPP Tat $_{\text {was }}$ estimated to be $20-30 \mu \mathrm{M}$ in the cells, about twice the physiological concentration. Cell leakage was negligible; cell viability and membrane integrity testing indicated that no significant toxicity was associated with pyrenebutyrate treatment. Ub-3A-CPP ${ }_{\text {Tat }}$ was also transduced into monkey COS-7 cells, demonstrating the versatility of this method.

The in-cell spectrum of wild-type ubiquitin showed extensive peak broadening relative to the in-cell spectrum of Ub-3A and included the G76 cross-peak observed for cleaved $\mathrm{Ub}-3 \mathrm{~A}$. This indicated that at least some of the wild-type ubiquitin existed in a C-terminally unconjugated state. The difference in peak intensity between the two spectra likely reflect the interaction of wild-type ubiquitin with endogenous proteins, since the mutated residues prevented binding with UIPs. A similar effect was seen in in-cell NMR experiments performed by using $X$. laevis oocytes [31].

Other methods of CPP-linked transduction were tested. CPPs linked to cargo proteins by using disulfide bonds [32] are cleaved in the cytosol by autonomous reduction. The ${ }^{1} \mathrm{H}\left\{{ }^{15} \mathrm{~N}\right\}$-HSQC spectrum of the B1 domain of streptococcal protein G (GB1) conjugated to $\mathrm{CPP}_{\mathrm{Tat}}$ and transduced into HeLa cells was well-resolved and virtually identical to that of a spectrum acquired in vitro. Similar results were obtained using Ub-3A.

A final delivery method was used to demonstrate the feasibility of studying drug-protein interactions. A $\left[U_{-}{ }^{15} \mathrm{~N}\right]$ labeled fusion protein consisting of $\mathrm{Ub}$ containing an $\mathrm{N}$-terminal $\mathrm{CPP}_{\text {Tat }}$ and C-terminal FKBP-12 domain was transduced into HeLa cells. Cleavage was predicted to be mediated by DUBs, which would release free FKBP12 into the cytosol. The resulting in-cell ${ }^{1} \mathrm{H}\left\{{ }^{15} \mathrm{~N}\right\}$ correlation spectum of FKBP12 was identical to the reference in vitro spectrum, whereas the contribution of $\mathrm{CPP}_{\mathrm{Tat}}-\mathrm{Ub}$ to the spectrum was minimal. It was concluded that DUB-mediated cleavage released free FKBP12 to yield an analyzable in-cell NMR spectrum while $\mathrm{CPP}_{\text {Tat }}-\mathrm{Ub}$ underwent $\mathrm{CPP}$-mediated aggregation within the cell.

The interaction of free FKBP12 with two immunosuppressant drugs, FK506 and rapamycin, were examined. Transduced HeLa cells were incubated with either FK506 or rapamycin. The changes observed in the in-cell ${ }^{1} \mathrm{H}_{-}{ }^{15} \mathrm{~N}$ correlation spectra obtained for both drugs were distinct from one another but consistent with the reference spectra, acquired in vitro, of FKBP12 complexed with each drug. The results showed that exogenously administered drugs entered the cells and formed specific complexes with FKBP12.

This work demonstrated that the technique of using cell penetrating peptides to deliver sufficient concentrations of isotopically labeled proteins into eukaryotic cells in order to perform high resolution in-cell NMR spectroscopy is effective for studying in-cell protein dynamics, protein-protein and protein-drug interactions.

\subsection{Molecular crowding}

Much concern has been generated over the physiological relevance of studying biological macromolecules by performing NMR on living cells. These concerns have focused on the colligative properties of the cellular interior, specifically viscosity and the presence of high concentrations of endogenous and over-expressed macromolecules, and the extent to which these characteristics of the cytosol will affect the resulting in-cell NMR spectra. To examine the effects of intracellular composition on the structure of in-cell target molecules, two 
classes of solutes are generally considered: large macromolecular species and small solventlike molecules. The first is expected to affect the diffusion and tumbling rates of the target because of frictional interactions, while the second may be responsible for altering the structure of the target through excluded volume effects.

Macromolecular crowding and solvent exclusion result in higher effective concentrations of macromolecules due to the reduction in water concentration. This can result in an increase in both specific and non-specific association reactions, including aggregation, which tend to broaden in-cell NMR signals. It can also promote folding; an inherently disordered protein lacking significant biological activity can be partially or completely folded under crowding conditions to generate a biologically active molecule [33] . Indeed, this may be a mechanism of regulating activity in species where, in the absence of crowding, no biological activity is present. Finally, the reduced concentration of water can alter structured water, which, in turn, can alter protein conformation and biological activity [34].

In vitro, the addition of co-solvents such as glycerol, or large molecular species such as bovine serum albumin (BSA) or polyvinyl pyrrolidone (PVP) are used to mimic the bulk solvent properties of the cytosol. While these species are ideally inert, one must evaluate the ability of these substances to interact with the targets and therefore interfere with the property or process being examined. Another method to mimic cytosolic conditions uses concentrated cell extracts or lysates. The problem here is the lack of cellular regulatory mechanisms that may be required for normal activity.

Selenko et al. [15] acquired the in-cell NMR spectrum of streptococcal protein G B1 domain (GB1) and found that the signal intensity was reduced $\sim 5$-fold and proton peak widths increased by $\sim 2.5$-fold relative to an equimolar in vitro spectrum of purified GB1. Analyses of $2 \mathrm{D}$ correlation spectra allowed the global structure to be deduced and the differential line broadening of individual residues to be evaluated. Hydrogen-bonded amide groups in secondary structural elements showed greater peak broadening than those in unstructured regions. This observation implies that the cellular environment affects the relaxation properties of hydrogen-bonded amide groups more strongly than those that are exposed to solvent and is in keeping with the idea that macromolecular crowding slows overall tumbling rates while solvent-exposed groups experience greater degrees of freedom [35].

To determine whether or not these observations are due to macromolecular crowding, comparative analyses were performed in vitro by acquiring NMR spectra of GB1 in 150-300 $\mathrm{mg} / \mathrm{mL}$ BSA. At the lowest BSA concentrations, the in vitro and in-cell spectra were virtually indistinguishable. At higher concentrations, a reduction in signal intensity and corresponding increase in proton peak widths was observed. The results suggest that properties of the intracellular environment can be simulated by using artificially crowded solutions.

To study how molecular crowding affects protein diffusion in response to recombinant protein over-expression, Slade et al. [36] used fluorescence recovery after photobleaching (FRAP) to monitor the diffusion of green fluorescent protein (GFP) in E. coli. In FRAP, a small area/volume of a cell containing fluorescent molecules is bleached using a laser and fluorescence recovery is monitored as unbleached molecules diffuse back into the bleached region. Slade et al. [36] used four different proteins, which covered a range of sizes and shapes: Tau-40 (45 kDa), maltose binding protein (42 kDa), calmodulin $(17 \mathrm{kDa})$ and $\alpha-$ synuclein $(14 \mathrm{kDa})$. In each case GFP was first expressed, followed by separate expression of each of the four proteins. The levels of GFP in each experiment were constant as monitored by SDS-PAGE. It was calculated that each co-expressed protein accounted for approximately $15 \%$ of the total intracellular protein. Regardless of the size and shape of 
each co-expressed protein, the diffusion rate of GFP showed no variation. These findings suggest that molecular crowding due to protein over-expression does not appreciably affect intracellular protein diffusion in bacteria and that in-cell NMR spectroscopy is an effective method for studying proteins in a biologically relevant environment.

\subsection{Cell viability}

In-cell NMR yields lower quality spectra than those obtained using highly purified samples typically due to low signal to noise ratios. This shortfall can be compensated for by increasing the intracellular concentration of the target, by increasing the number of scans per experiment and by using a ultrasensitive cryoprobe. Stabilizing the cells by using known cell protectants, such as glycerol or sucrose [37], or alginate encapsulation [38], may also extend the in-cell NMR acquisition time. Finally, the sensitivity of the resulting in-cell spectrum may be increased by using transverse optimized spectroscopy (TROSY-HSQC) for high molecular weight complexes that have slow tumbling times.

Another important factor that limits the acquisition time of in-cell NMR experiments is cell lysis, which results in leakage of labeled target from the cells [37]. Xie et al. [35] added glycerol (up to $10 \%$ ), to samples as a cryoprotectant for prolonged storage of the cells at -80 ${ }^{\circ} \mathrm{C}$. Adding glycerol to the NMR buffer maintains the viability of $E$. coli cells at room temperature for more than four hours at densities sufficient to obtain in-cell NMR spectra and to minimize cell lysis. As a result, the NMR signal from the $\left[U_{-}{ }^{15} \mathrm{~N}\right]$-protein in the supernatant did not exceed the noise level.

To minimize cellular degradation during their study of the tau protein, Bodart et al. [18] suspended Xenopus oocytes in a 20\% Ficoll solution, which allowed the cells to remain stable overnight [39]. Control experiments showed no tau in the extracellular medium. This work demonstrated a method for extending the lifetimes of cells in the NMR tube, a critical prerequisite for collecting data at physiological concentrations.

Another method to assess bacterial cell viability is by using a standard colony plating test. In this test, the number of colonies grown on antibiotic selection plates inoculated with the incell sample before NMR spectroscopy is compared with the number of colonies grown using cells plated after acquiring experimental data. Colonies are counted by using a molecular imager. The cells are considered to be viable if the number of colonies on the plates are within $10 \%$ of each other [40].

In-cell NMR is an effective tool for studying proteins in their native environment. However a consequence of this technique is the issue of protein leakage which can lead to sharp signals from the protein molecules in the less viscous extracellular medium, thereby masking the broader signals obtained from protein in the cytosol. To ensure that the NMR signal arose from proteins located inside the cell, Li et al. [38] collected an ${ }^{1} \mathrm{H}\left\{{ }^{15} \mathrm{~N}\right\}$-HSQC spectrum of in-cell sample supernatant immediately after preparing the cells and immediately after acquiring the spectrum. A comparison between the spectra obtained using two proteins, the disordered, $14 \mathrm{kDa} \alpha$-synuclein $(\alpha-\mathrm{SYN})$, and the $7 \mathrm{kDa}$ globular protein chymotrypsin inhibitor-2 (CI2) showed that CI2 leaks from the cell, 20\% being lost as confirmed by SDS-PAGE analysis, and $\alpha$-SYN remains in-cell with only small metabolites found in the spectrum of the supernatant. To improve the in-cell spectrum of $\alpha-\mathrm{SYN}, \mathrm{Li}$ et al. [38] used an alginate encapsulation method [41] to stabilize the cells, which, in turn, yielded a clean ${ }^{1} \mathrm{H}\left\{{ }^{15} \mathrm{~N}\right\}$-HSQC for $\alpha$-SYN. Encapsulating CI2 resulted in no in-cell NMR signal being detected despite an increase in acquisition time. 


\subsection{Rotational diffusion in the cell}

The disappearance of the $\mathrm{CI} 2$ signal was reasoned to be because of the altered dynamics induced by either CI2 binding non-specifically to larger species in the cell or from the increased viscosity of the intracellular medium; both processes would lead to a decrease in the rotational diffusion of the protein. The rotational diffusion of proteins in solution affects the longitudinal (R1) and transverse (R2) relaxation rates of NMR active nuclei. Longitudinal relaxation rates determine how fast nuclear magnetization comes to equilibrium, while transverse relaxation rates determine the linewidth of the NMR signal. For the ${ }^{1} \mathrm{H}\left\{{ }^{15} \mathrm{~N}\right\}$-HSQC experiment, if ${ }^{1} \mathrm{H}$ and ${ }^{15} \mathrm{~N}$ transverse relaxation rates are too fast the resonances tend to be too broad to detect.

The extent of non-specific interactions with cellular components depends on the nature of the protein, the extent of protein over-expression and the cell growth conditions, all of which can be modified as necessary to improve the in-cell NMR signal. To test how R1 and R2 vary with viscosity under the conditions of macromolecular crowding, Li et al. [38] used poly(vinyl pyrrolidone (PVP) as a macromolecular crowding agent. R1 changed very little between buffer and PVP for all proteins tested. For the intrinsically disordered $\alpha \mathrm{SN}$ protein there was a 1.5 to 6-fold increase in R2 measured in PVP compared to buffer, while the values for CI2 increased 3 to 40 -fold. R1 and R2 measurements made using different solvents indicated that the globular protein CI2 is more sensitive to viscosity than $\alpha \mathrm{SN}$. The cause for the differences in relaxation rates may be linked to local and global motions within each protein. CI2 is more sensitive to global motions due to its rigid structure as opposed to $\alpha \mathrm{SN}$, which is unstructured and influenced more by local rotational motions. The findings show that in-cell NMR is better suited to study disordered proteins than globular ones.

Li et al [42] have used NMR spectroscopy to monitor the effect of PVP on the translational and rotational diffusion of the globular protein CI2. Translational diffusion was monitored by using a heteronuclear stimulated gradient echo sequence [43] and rotational diffusion was assessed from the ${ }^{15} \mathrm{~N}$ R2/R1 ratio [44]. According to the classical description of diffusion [45], both translational and rotational diffusion are inversely proportional to the viscosity. This relationship breaks down when PVP is used as a macromolecular crowding agent. In this case, rotational diffusion is affected less than the translational diffusion. This effect was explained by the fact that large crowding molecules do not make extensive contact with the protein surface because of steric effects and thus are not as effective as small molecules, such as glycerol, in decreasing protein rotational diffusion. Inside the cell, macromolecular crowding is provided by large biological molecules, which will have a similar effect on rotational diffusion, thus improving the sensitivity of in-cell NMR spectroscopy.

\section{Applications}

Much of the early work in the field of in-cell NMR utilized E. coli as the host cell. E. coliare easy to handle and grow very rapidly. Proteins are uniformly labeled with NMR-active isotopes, primarily ${ }^{13} \mathrm{C}$ and ${ }^{15} \mathrm{~N}$, and over-expressed to high enough intracellular levels to yield high quality HSQC spectra with little or no interfering background. Furthermore, the ability to selectively label proteins and grow cells in $\mathrm{D}_{2} \mathrm{O}$-based media provides the capability to study high molecular weight proteins at physiological conditions. However, while bacterial cells are ideal for simulating an intracellular environment for studying eukaryotic proteins, in that they present the lowest potential for intrinsic binding partners, they lack the inherent ability to affect post-translational modifications and to provide compartmentalization for selective activity.

In-cell NMR spectroscopy in eukaryotic cells has been limited to very large and mechanically manipulable cells, such as Xenopus laevis oocytes. Studies employing 
eukaryotic cells are hampered by the difficulties in over-expressing isotopically labeled proteins inside the cell, the inability to regulate post-translational modification activities and the inefficient delivery of labeled proteins to the cytosol. Initially isotope-labeled molecules were microinjected into the cytosol of these cells. This delivery method was improved by using active transport of isotope-labeled molecules into the cell by linking them to cell penetrating peptides. Recently much progress has been made to extend in-cell NMR to many cell types including primary cells and to take advantage of endogenous biochemical activity present in these cells to identify protein-protein and protein-DNA interactions, and sites and mechanisms of post-translational modifications.

\subsection{Structure determination}

The ability to determine high resolution 3-dimensional structures of proteins in solution is one of the prime features of NMR spectroscopy. To accomplish this by acquiring spectra from living cells represents one of the next great steps in the evolution of structural biochemistry.

3.1.1 De Novo 3D Protein Structure Determination-The low sensitivity of protein NMR requires very long sampling times: typical NMR experiments collect data for 1-2 days. Without fresh supplies of nutrients and gases, along with waste removal, E. coli cells cannot survive for that long. To minimize the sampling time, Sakakibara et al. [46] employed a novel non-linear sampling scheme [18-20] to solve the structure de novo, of TTHA1718, a 66 amino acid, putative heavy-metal binding protein from T. thermophilus. By combining this scheme with maximum entropy processing $[47,48]$ the time required to collect sufficient multidimensional data was reduced to several hours.

TTHA1718 was overexpressed in uniform isotopic-labeling medium from E. coli to a concentration of 3-4 mM. Control experiments demonstrated that the NMR signal originated from protein within the cells. 63 out of 66 backbone resonances were assigned by using six 3D triple-resonance experiments with samples prepared freshly for each experiment. $86 \%$ of $\mathrm{H} \alpha, 71 \%$ of $\mathrm{H} \beta$ and $34 \%$ of the aliphatic ${ }^{1} \mathrm{H} /{ }^{13} \mathrm{C}$ side chain resonances were identified. NMR assignments on in vitro purified protein were obtained to compare with the in-cell assignments. Colony plating tests showed that after 6 hours of data acquisition the viability of the bacteria was $85 \%$.

To improve the signal to noise ratio, each $3 \mathrm{D}$ experiment was performed several times and the data sets were combined to enhance the protein signal. The 3D experiments were bracketed by a $2 \mathrm{D}{ }^{1} \mathrm{H}\left\{{ }^{15} \mathrm{~N}\right\}$-HSQC experiment, which acted as a control to ensure that only data collected from intact cells were included in the combined data set. Each control spectrum following a 3D experiment was compared against the original reference HSQC spectra collected at the beginning of the run. If the control spectrum was significantly different from the reference spectrum, the 3D spectrum that was collected prior to the control spectrum was not added to the composite data.

Side chain methyl groups of Ala, Leu and Val were selectively ${ }^{13} \mathrm{C}$-labeled allowing $78 \%$ of their side chain resonances to be assigned. In addition, out of a possible total of 148 NOEs involving methyl groups 69 of 89 long range NOEs were assigned. NOE distance restraints, backbone torsion restraints and restraints for hydrogen bonds were incorporated into the calculation of a 3D structure for TTHA1718 using CYANA [49,50]. The final calculated structure is similar to the structure determined in vitro for purified TTHA1718, and had a root mean squared deviation (rmsd) of $0.96 \AA$ and a backbone rmsd of $1.16 \AA$ from the in vitro structure. 
This study demonstrates the feasibility of determining high resolution 3D structures of proteins in living bacterial cells. The results were possible because of innovations that allowed rapid data collection and unambiguous identification of long range NOE interactions based on selective labeling of methyl groups. Furthermore, when TTHA1718 was over-expressed to $1.2-1.5 \mathrm{mM}$ and $0.6-0.8 \mathrm{mM}, 74 \%$ and $61 \%$ of the respective NOE cross-peaks used to calculate the structure were observed. This suggests that in-cell structure determination in eukaryotic cells may be possible since labeled proteins can be introduced into Xenopus oocytes at concentrations up to $0.7 \mathrm{mM}$ [15]. Eukaryotic cell stability is still a limiting factor and new methods of either NMR technology and/or sample preparation are required before in-cell NMR protein structure determination in eukaryotic cells becomes possible [44].

\subsection{Protein-protein interactions}

Protein-protein interactions are the mainstay of biological activity. One of the most difficult challenges in studying protein-protein interactions in cells arises because proteins bind many types of ligands, from small effectors molecules such as small metabolites to large macromolecules such as nucleic acid polymers and other proteins. The affinities with which these ligands are bound vary over a broad range. To further dissect the differences between in-cell and in vitro studies of protein-protein interactions, we can divide the interactions between expressed proteins and other intracellular molecules into two parts: specific interactions with affinities lower than $10 \mu \mathrm{M}$ and non-specific interactions with affinities much greater than $10 \mu \mathrm{M}$.

In order to detect specific interactions by using in-cell NMR spectroscopy the interactor proteins have to be present in a stoichiometric ratio with the target protein so that the bulk of the labeled population is bound. Typically, target proteins are over-expressed to concentrations 10 to 100 -fold greater than their physiological concentrations, which results in a large population of free protein and no changes in the NMR spectrum. Thus, we can largely ignore the contribution of undesired specific interactions between the target protein and intracellular binding partners to the resulting in-cell NMR spectrum. By using selectively inducible over-expression, specific interactor proteins can be introduced later at concentrations that are comparable to that of the labeled protein, thereby giving rise to specific interactions inside the cell that are detectable by using NMR.

Non-specific interactions between labeled proteins and intracellular molecules are omnipresent and establish the proper physiological environment for the labeled proteins that uniquely distinguishes in-cell NMR studies from those using in vitro techniques. This is best evidenced by small differences in the NMR spectra and solution structures of proteins measured in cells and in vitro [46]. The concentrations of molecules inside eukaryotic and prokaryotic cells are very similar to each other; as a result we do not expect that the contribution of non-specific interactions will be dramatically different in these two cases and that the in-cell NMR spectra of cytosolic proteins acquired in either cell type will also be very similar.

3.2.1 Structural interactions-Burz et al. [51,52] developed an in-cell NMR-based method for mapping the structural interactions (STINT-NMR) that underlie protein-protein complex formation. The method entails sequentially expressing two (or more) proteins within a single bacterial cell in a time-controlled manner [53] and monitoring their interactions using in-cell NMR spectroscopy [4]. The resulting NMR data provide a complete titration of the interaction and define structural details of the interacting surfaces at atomic resolution. Unlike the case when interacting proteins are simultaneously overexpressed in the labeled medium, in STINT-NMR the spectral complexity is minimized 
because only the target protein is labeled with NMR-active nuclei, which leaves the interactor protein(s) cryptic.

The target protein, whose NMR structure must be known, is first overexpressed on uniformly labeled $\left(U_{-}{ }^{15} \mathrm{~N}\right)$ medium to yield a high-resolution, isotope-edited heteronuclear single quantum coherence ${ }^{1} \mathrm{H}\left\{{ }^{15} \mathrm{~N}\right\}$-HSQC backbone spectrum of the target protein inside the bacterial cells. The growth medium is changed, and the unlabeled interactor is overexpressed. As the interactor binds to the target, the HSQC spectrum of the target changes to reflect the different chemical environments of those residues affected by the binding interaction. The corresponding changes in the peak widths and chemical shifts of the target protein resonances define the interface between the protein and its ligand (interactor), providing atomic resolution information on the interactions.

Changes in chemical shifts and differential broadening of some assigned peaks may be more widespread, however, reflecting rearrangements of secondary structural elements, or a global or allosteric change in the conformation of the target. To assess accurately the changes in the NMR spectrum of a target molecule upon complexation with an interactor molecule, it is imperative that the resonance assignments of the target protein be known beforehand, and that the target is stable and well-behaved in the absence of the interactor protein.

The efficacy of this method was demonstrated by over-expressing $\left[U_{-}{ }^{15} \mathrm{~N}\right]$ ubiquitin followed by over-expression of either one of two ubiquitin ligands containing the Ubiquitin Interacting Motif (UIM) [54]: a 28-amino acid peptide from ataxin 3 (AUIM; $4 \mathrm{kDa}$ ) or the Signal-Transducing Adapter Molecule (STAM2 [55]; 50 kDa) in unlabeled medium. AUIM binds ubiquitin in vitro with $\sim 230 \mu \mathrm{M}$ affinity [56,57] and STAM2, which contains two ubiquitin interacting surfaces, binds with a higher $(\sim 10 \mu \mathrm{M})$ overall affinity. These two systems simulated a range of protein-protein interaction affinities and molecular weights.

The ${ }^{1} \mathrm{H}\left\{{ }^{15} \mathrm{~N}\right\}$-HSQC spectrum of ubiquitin, which was maintained at a single concentration, changed as the concentration of interactor was increased (Fig. 3). The chemical shift changes were mapped onto the three-dimensional structure of ubiquitin. Peaks that have substantial $(>0.1 \mathrm{ppm})$ chemical shift changes are exclusively from surface-exposed amides. Control experiments using a mutant AUIM, which does not bind to ubiquitin, demonstrated that the chemical shifts changes result from specific interactions and not merely overexpression of the interacting molecule.

The method is limited primarily by the concentration level of interacting protein that can be achieved and can be used to study interactions with proteins whose structure is unknown, since only the target protein is labeled. It can be used to study proteins that are difficult to purify or are proteolytically labile, since there is no need for purification. Another limiting consideration is the integrity of the interacting proteins. For example, over-expressed proteins may degrade into components that bind non-specifically to each other, thereby presenting multiple and/or incorrect interaction surfaces. For this reason, the target should be stable over the course of the experiment. Should sample stability become questionable, SDS-PAGE and Western blots can be used to assess the extent of degradation.

3.2.2 Drug screening-Xie et al. [58] developed an in-cell NMR spectroscopy-based screening procedure, Screening of small Molecule Interactor LIbrary (SMILI-NMR), to rapidly screen for compounds capable of disrupting and enhancing specific interactions between two or more components of a biomolecular complex. SMILI-NMR utilizes STINTNMR [51,52] technology to produce biomolecular complexes inside the cell in which one of the constituent proteins is uniformly $\left[U_{-}{ }^{15} \mathrm{~N}\right]$ labeled with NMR-active nuclei. The 
formation of high-affinity ternary complexes is observed by monitoring the in-cell NMR spectrum of the labeled protein. STINT-NMR analyses identify changes in structure induced by binding of a small drug-like molecule that disrupts or enhances the stability of the complex and reveal biologically relevant, functional interaction surfaces. In this way, STINT-NMR serves as a direct assay for protein-drug interactions, identifying small druglike molecules that bind to this surface and facilitating high throughput screening.

A system of two interacting proteins, FKBP and FRB, was used as a model to show the effectiveness of SMILI-NMR to screen small molecules that facilitate heterodimerization. The FKBP-FRB interaction constitutes one of the immunomodulatory systems in mammalian cells [59]. In complex with rapamycin, a macrolide antifungal antibiotic currently undergoing clinical trials for a variety of cancer treatments [60,61], FKBP binds to FRB. When $\left[U_{-}{ }^{15} \mathrm{~N}\right]$-FKBP was over-expressed in bacterial cells, the ${ }^{1} \mathrm{H}\left\{{ }^{15} \mathrm{~N}\right\}$-HSQC spectrum showed no well-resolved peaks, implying that the single species was part of a large complex and therefore invisible to NMR. When unlabeled FRB was then over-expressed in the same cells, the NMR spectrum of FKBP became evident but only at the highest FRB concentrations, indicating the formation of a complex. Similar results were obtained when $\left[U_{-}{ }^{15} \mathrm{~N}\right]-\mathrm{FRB}$ and unlabeled FKBP were sequentially over-expressed in the same cells. These observations demonstrated that creating a proper protein complex is necessary for high-resolution studies.

Adding rapamycin to the cell suspension resulted in visible changes in the ${ }^{1} \mathrm{H}\left\{{ }^{15} \mathrm{~N}\right\}$-HSQCspectrum of $\left[U_{-}{ }^{15} \mathrm{~N}\right]-\mathrm{FKBP}$ indicating the formation of a high-affinity ternary complex between FKBP-rapamycin and FRB (Fig. 4). Adding rapamycin to cells overexpressing labeled FKBP in the absence of FRB or labeled FRB in the absence of FKBP did not produce an NMR spectrum. In each case, co-expression of the second protein was required to generate an in-cell NMR spectrum.

A dipeptide chemical library [62] composed of $17 \times 17$ dipeptides [62,63] was chosen to provide a collection of compounds that are capable of interacting with the target molecule at a detectable level. These compounds provided suitable starting points for subsequent optimization into credible drug candidates [64] and were considered as potential sources of novel lead structures. Dipeptides have been shown $[63,65]$ to be an excellent starting point for drug design since 1) they can be prepared at low cost, 2) a library containing only 289 compounds can provide a data set that spans a broad spectrum of physicochemical properties, 3) no deconvolution is required to identify the lead structures [64], and 4) dipeptides can pass through the cell membrane and interact with the target protein directly in vivo $[66,67]$.

A standard procedure called the matrix method, in which compounds located in one row or one column of a matrix plate were mixed and tested, was used to screen the library. Individual mixtures were examined for their ability to change the in-cell NMR spectrum of the FKBP-FRB biocomplex. Samples exhibiting similar spectral changes, located at the intersection of rows and columns, were used in the second round of screening to deconvolute and validate the initial findings. In this way, a matrix of $289(17 \times 17)$ compounds were screened by examining $34(17+17)$ samples.

Most of the dipeptide mixtures showed no interaction with the FKBP target. The mixture of $\mathrm{A}-\mathrm{X}$ (where $\mathrm{X}$ is all possible amino acids) elicited a totally different spectrum from that of the rapamycin-induced ternary complex (Fig. 4). Formation of the dipeptide-induced complex resulted in extreme broadening and the disappearance of some peaks in the NMR spectrum at the highest concentration used. The mixtures of D-X, T-X, L-X, X-E, X-I, X-A, $\mathrm{X}-\mathrm{T}$ also caused a similar broadening of the spectrum. Thus, the dipeptides located at the 
intersection of rows, A-X, D-X, T-X, L-X and columns X-E, X-I, X-A, X-T were screened in a second round and titrated into cells individually. Only A-E showed the same interaction with FKBP suggesting that A-E facilitated heterooligomerization of FKBP and FRB. Competition experiments with rapamycin confirmed that A-E binds specifically to the FKBP-FRB complex. Further confirmation that A-E exhibited biological activity comparable to that of rapamycin was obtained by using a yeast growth assay.

SMILI-NMR provides an important means to bridge the gap between biochemical identification of small ligands capable of interfering with target biocomplexes and the biological activity resulting from the inhibition of cellular processes by these ligands. The method requires minimal sample preparation and eliminates the need for extensive protein purification. Furthermore, SMILI-NMR can be automated by making use of robotic HTS accessories available for modern NMR spectrometers, such as liquid handlers and NMR tube changers.

3.2.3 Metabolic processing-In order to investigate proteins under intracellular environmental conditions Sakai et al. [31] injected X. laevis oocytes with labeled proteins. The experiments highlight the effects of protein-protein interactions on NMR spectra and the difficulty in obtaining in-cell spectra by using native proteins. They also report the first real-time intracellular observations of enzymatic activity.

Uniformly $\left[U_{-}{ }^{15} \mathrm{~N}\right]$ labeled ubiquitin and its derivatives were expressed and purified in bacteria [68]. The purified protein was microinjected into $X$. laevis oocytes to a maximum final concentration of $\sim 100 \mu \mathrm{M}$. The magnitude of the signal for the ${ }^{1} \mathrm{H}\left\{{ }^{15} \mathrm{~N}\right\}$-HSQC spectrum of wild-type ubiquitin injected into the oocytes was very weak. Control experiments verified that the ubiquitin spectrum originated from an intracellular environment and not from labeled protein that had leaked from the cells into the surrounding media. To counteract this non-desirable interference, cells were washed prior to loading into the NMR tube. A series of ${ }^{1} \mathrm{H}\left\{{ }^{15} \mathrm{~N}\right\}$-HSQC spectra were obtained and between each measurement the cells were removed from the NMR tube and washed. There was a $13 \%$ loss in peak intensities after each wash indicating that the observed NMR signal is mostly derived from intracellular protein.

Experiments performed using a series of mutant ubiquitins, in which residues implicated in binding ubiquitin-interacting proteins (UIPs), L8, I44 and V70 [29], were changed to alanines. The results showed that the in-cell ${ }^{1} \mathrm{H}\left\{{ }^{15} \mathrm{~N}\right\}$-HSQC spectrum of ubiquitin could be largely recovered when the UIP interface is perturbed. The perturbation disrupts proteinprotein interactions, which decreases peak broadening and resolves the spectrum. Ubiquitin molecules carrying single mutations affecting the UIP binding site (L8A-D77, I44A-D77 and V70A-D77) partially restored the in-cell ubiquitin ${ }^{1} \mathrm{H}\left\{{ }^{15} \mathrm{~N}\right\}$-HSQC spectrum and the protein containing all three mutations ((L8A, I44A, V70A)-D77) dramatically improved the spectrum. Thus, the inability to resolve an in-cell spectrum for ubiquitin results from its interacting with endogenous UIPs, preventing a sufficient in-cell concentration of free ubiquitin for analysis by NMR spectroscopy.

The ubiquitin used in this study contained a C-terminal D77 residue (Ub-D77), whereas mature ubiquitin has a G76 in that location [69]. The D77 protein, therefore, mimics a ubiquitin precursor and can act as a substrate for Ubiquitin C-terminal hydrolase (UCH). The cross peaks attributed to the G76 and D77 amide groups are missing from the in-cell spectrum of Ub-D77, and a single peak corresponding to wild-type G76 is present. This suggests that the G76-D77 peptide bond in this mutant is cleaved in the oocyte. 
By pre-injecting oocytes with ubiquitin aldehyde, which specifically inhibits UCH [69], the in-cell spectrum of ${ }^{15} \mathrm{~N}-\mathrm{Ub}-\mathrm{D} 77$ showed G76 and D77 cross peaks and a G76 signal that was weaker than control cells pre-injected with water that displayed no G76 and D77 cross peaks. Further experiments showed a dose dependence on residual UCH activity. Thus, by pre-injecting oocytes with ubiquitin aldehyde, $\mathrm{UCH}$ activity was inhibited, thereby reducing and curtailing ubiquitin processing. These observations suggest that in-cell NMR spectroscopic analyses of metabolic processing may be possible under selective conditions.

Sakai et al. [56] also microinjected $\left[U_{-}{ }^{15} \mathrm{~N}\right]$ labeled calmodulin into oocytes. The incell ${ }^{1} \mathrm{H}\left\{{ }^{15} \mathrm{~N}\right\}$-HSQC spectrum of calmodulin, acquired without $\mathrm{Ca}^{2+}$ in the buffer, resembled that of apo-calmodulin acquired in vitro, except that the peaks were broader, indicating that the majority of the in-cell calmodulin was $\mathrm{Ca}^{2+}$-free. When an excess of $\mathrm{Ca}^{2+}$ was co-injected with the protein, the overall spectrum changed and the resulting cross peaks were further broadened, precluding exact assignments of individual resonances. However, more than 10 cross peaks that are consistent with those observed for $\mathrm{Ca}^{2+}$-bound calmodulin were identified. Since $\mathrm{Ca}^{2+}$-bound calmodulin is more likely to interact with downstream effector proteins [70] than apocalmodulin, the reduced spectral quality observed in the presence of $\mathrm{Ca}^{2+}$ suggests interactions between injected and endogenous proteins.

\subsection{Post-translational modifications}

Post-translational modifications (PTMs) of proteins such as phosphorylation, ubiquitination, sumoylation and glycation are necessary to regulate biological processes. Several studies have taken advantage of in-cell NMR spectroscopy to identify and to examine the ramifications of phosphorylated sites on proteins. The results show that post-translational modifications can be studied in eukaryotic cells where these modifications commonly occur, and in prokaryotic cells, where, by appropriately engineering the transcriptional machinery of the cells, the effects of PTMs on protein structure can be examined without competing reactions, in effect, turning the bacteria into "cellular test tubes".

3.3.1 Identifying phosphorylation sites-Certain patterns of protein phosphorylation contribute to different pathologies [71]. X. laevis oocytes, which contain many kinases, can potentially be used to study protein phosphorylation in vivo. Bodart et al. [61] used in-cell NMR spectroscopy to examine the phosphorylation pattern of the neuronal protein, tau, in Xenopus oocytes. Tau is involved in stabilizing microtubules and constitutes a major component of the intracellular tangles of neurons in the cells of Alzheimer diseased patients.

The bulk of the in-cell ${ }^{1} \mathrm{H}\left\{{ }^{15} \mathrm{~N}\right\}$-HSQC NMR spectrum acquired for tau was consistent with it being bound to tubulin. The resolution and number of the resonance peaks increased following mechanical homogenization of the sample. Some peaks were attributed to phosphorylated residues of tau. Comparing the in-cell spectrum to an in vitro spectrum of tau phosphorylated by PKA [72], indicated that the major peak observed in the in-cell spectrum was not generated by this kinase.

Another kinase present in the oocyte, Gsk3 $\beta$ [73], was examined to see if it was responsible for generating the major peak. Gsk3 $\beta$ was overexpressed, purified and used to phosphorylate PKA-phosphorylated tau in vitro. The spectrum obtained from lysed cells that had been injected with PKA/Gsk3 $\beta$ phosphorylated tau indicated that the major site observed in the in-cell spectrum was not generated by this kinase either. By examining the cell lysate of this sample at a lower threshold, a minor peak corresponding to phosphorylated Ser214 was identified and attributed to in-cell PKA-mediated phosphorylation. Thus, in-cell NMR spectroscopy in Xenopus oocytes can identify individual phosphorylated residues and the enzyme responsible for a specific post-translational modification. Importantly, this work opens up the possibility of the use of specific probes to study biochemically modified sites. 
3.3.2 Kinetic mechanism for Casein Kinase 2-Selenko et al. [74] used in-cell NMR to observe real time enzymatic reactions in X. laevis egg extracts and oocyte cells. The study focused on the phosphorylation of substrates at adjacent sites by casein kinase 2 (CK2). This naturally abundant kinase is constitutively active in eukaryotic cells. Extensive mutational analyses were performed to determine the chemical nature and location of amino acids surrounding the modification sites that are critical for the phosphorylation reactions.

Experiments were performed using a model substrate, $\mathrm{XT}_{111-132} \mathrm{~GB} 1$, in which the regulatory region of the viral SV40 large $\mathrm{T}$ antigen, $\mathrm{XT}_{111-132}$, was fused to the $\mathrm{B} 1$ domain of streptococcal protein G (GB1). The GB1 domain acted as a C-terminal tag [75] and facilitated the solubility of the fusion protein. The protein was uniformly $\left[U_{-}{ }^{15} \mathrm{~N}\right]$ labeled and purified from bacterial cells [15]. CK2 phosphorylates serine residues 111 and 112 in this construct, and this modification has been shown to regulate the transportation of full length protein into the nucleus $[76,77]$.

Initially, ${ }^{1} \mathrm{H}\left\{{ }^{15} \mathrm{~N}\right\}$-HSQC spectra, acquired in vitro by using labeled substrate and recombinant CK2, after 60 minutes, revealed that $\mathrm{S} 112$ was exclusively phosphorylated as indicated by a large change in the chemical shift of the S112 resonance cross-peak. The magnitude of the change was consistent with that observed between phosphorylated and unphosphorylated amino acids [78]. This modification proceeded until the peak corresponding to unphosphorylated S112 had disappeared, indicating that all of the S112 sites were phosphorylated, at which time phosphorylation of S111 commenced. After 100 minutes, a population of singly and doubly phosphorylated substrate was observed. S111 phosphorylation continued until all of the substrate had been modified at both sites $(\sim 140$ minutes).

CK2 phosphorylation of $\mathrm{XT}_{111-132} \mathrm{~GB} 1$ was shown to proceed in a two-step process. Since singly modified substrate was observed at intermediate times during the course of the reaction, it was rationalized that CK2 must dissociate from the mono-phosphorylated substrate prior to phosphorylating the second site. This is because the substrate-CK2 complex is too large to be detected, therefore any substrate detected must be in the free state. The ability of the phosphorylation process to be selective enough to only phosphorylate one site was postulated as necessary to maintain the ultrasensitive nature of the signaling pathway

The reaction was examined by using $X$. laevis egg extracts [79] and by microinjecting labeled substrate into $X$. laevis oocytes, both of which contain endogenous CK2 [80]. Changes in the cross peak resonances of the modified residues in NMR spectra acquired using egg extracts were indistinguishable from those obtained in vitro. In oocytes, the NMR spectral changes were also consistent with stepwise phosphorylation of S112, release of the mono-phosphorylated substrate and the phosphorylation of S111. Thus, CK2 phosphorylated $\mathrm{XT}_{111-132} \mathrm{~GB} 1$ via the same mechanism both in vitro and in vivo.

The study affirmed that in-cell NMR spectroscopy has advantages over traditional methods that might be used for analyzing protein phosphorylation in vitro. The NMR spectra obtained represented the direct detection of phosphorylated substrate residues. The signal does not depend on the location of the modified residue in the substrate or the number of substrates. The NMR process allows for the phosphorylation reaction to be studied over a period of time and the magnitude of the NMR signal provides information on the relative population of the different states of phosphorylation. This work demonstrated that other post-translational modifications that produce distinctive NMR spectra can potentially be studied by using in-cell NMR. 
3.3.3 In-cell biochemistry-Burz and Shekhtman [81] developed an in-cell methodology to introduce post-translational modifications (PTMs) onto interactor proteins in bacterial cells and to identify the changes in the interaction surface of a target protein when bound to the biochemically modified interactors. Modifying the interactor protein causes structural changes that manifest on the interacting surface of the target protein and these changes are monitored by using STINT-NMR [51,52]. The method was used to study the phosphorylation of tyrosine residues on the Signal-Transducing Adapter Molecule 2 (STAM2) and Hepatocyte growth factor-regulated tyrosine kinase substrate (HRS), and identify changes in the interaction surface of ubiquitin resulting from these post-translational modifications. The work demonstrated that post-translational modification of over-expressed proteins in bacterial cells can be regulated by tight temporal control over protein expression, a process dubbed "in-cell biochemistry".

STAM2 and HRS are components of an endocytic pathway present in eukaryotic cells. Each binds ubiquitin via a Ubiquitin Interacting Motif (UIM) [82]. In addition, STAM2 has a VHS domain capable of binding ubiquitin [57]. Evidence suggests that receptor sorting through endocytosis and subsequent degradation is controlled by ubiquitination of both the internalized receptors and components of the endocytic machinery [83].

To study ubiquitin binding to STAM2 and HRS, $\left[U_{-}{ }^{15} \mathrm{~N}\right]$-ubiquitin over-expression was induced prior to or following 3 or 4 hours of over-expression of STAM2 or HRS alone, or co-expression of both. STAM2 and HRS were phosphorylated by inducing over-expression of the constitutively active Src-family tyrosine-kinase, Fyn, for the final 2 hours of STAM2, HRS, or STAM2-HRS over-expression. STAM2 and HRS phosphorylation were confirmed by using Western blots and mass spectroscopic analyses.

The STINT-NMR spectra of ubiquitin revealed no changes in the interaction surface when bound to non-phosphorylated or phosphorylated HRS (Fig. 5). The spectrum of ubiquitin interacting with STAM2 revealed that a smaller surface is involved in the interaction with phosphorylated STAM2, corresponding to the loss of the interaction surface attributed to the VHS domain (Fig. 5). Mutational analysis revealed that two STAM2 tyrosines, Y371 and Y374, located in the conserved ITAM domain, were responsible for these changes. The ITAM domain has been identified as necessary for tyrosine phosphorylation of STAM2 by Jak1 [84].

A similar result was obtained for the interaction between ubiquitin and the STAM2-HRS heterodimer: Ubiquitin interacted with the phosphorylated ternary complex in much the same way that it interacted with phosphorylated STAM2 and phosphorylated HRS, involving contact with only the UIMs of both interactor proteins (Fig. 5). The commensurate weakening of the binding due to the loss of the second interaction surface is consistent with the idea that phosphorylation mediates the disassembly of ubiquitin-mediated scaffold complexes during endocytosis.

The introduction of in-cell biochemistry using STINT-NMR facilitates biochemical modification and examination of protein-protein interaction surfaces at the atomic level. The ability to control PTMs in an environment that normally lacks the ability to provide such modifications, i.e. bacterial cells, affords an opportunity to examine the effects of PTMs on protein structure without competing reactions. The methodology can be applied to any stable target molecule and may be extended to include other post-translational modifications.

\subsection{In-cell NMR of nucleic acids and protein-nucleic acid interactions}

An ongoing part of structural biology is to understand how genetic material is utilized during cellular processes. The extension of in-cell NMR spectroscopy to include nucleic 
acids and protein-nucleic acid interactions is critical to advancing this area of study. In-cell NMR studies of nucleic acids have been difficult due to the inability to over-express and label small DNA and RNA fragments inside the cell and the intrinsic instability of these fragments in a cellular milieu. Microinjecting labeled RNA and DNA fragments into $X$. laevis oocytes, which are largely devoid of DNAse and RNAse activity, circumvents these problems and permits the study of these structures by using in-cell NMR spectroscopy. To date, the study of protein-nucleic acids interactions inside cells has been limited to nonspecific interactions.

3.4.1 Nucleic Acids-Hansel et al. [85] extended in-cell NMR spectroscopy to the study of nucleic acids (NA) by injecting uniformly double labeled $\left({ }^{13} \mathrm{C}\right.$ and $\left.{ }^{15} \mathrm{~N}\right)$, synthetic $\mathrm{d}$ (GCGAAGC) DNA and r(GGCACUUCGGUGCC) RNA hairpins into $X$. laevis oocytes. The corresponding in-cell $\left[{ }^{15} \mathrm{~N}-{ }^{1} \mathrm{H}\right]$-SOFAST-HMQC, HSQC and $\left[{ }^{13} \mathrm{C}-{ }^{1} \mathrm{H}\right]-\mathrm{CT}$-TROSY spectra showed line broadening relative to spectra acquired in vitro, effects that were attributed to the increased viscosity and heterogeneity of the oocyte. Over time, the intensity of the DNA aromatic resonance peaks decreased and new peaks emerged (Fig. 6). Mass spectroscopic analyses indicated that the injected DNA was degraded to mononucleotides in the oocyte. Most of the resonances of the in-cell RNA spectrum decreased over time as well, the exceptions being U6 and U7 located in the flexible loop [86,87], but did not give rise to new peaks with chemical shifts characteristic of isolated nucleotides (Fig. 6). This suggested that rather than being completely degraded the RNA interacted with large cellular components.

To arrest the degradation of the DNA samples, modified substrates were prepared that replaced the first and second phosphate groups with phosphorothioate groups. The resistance of these modified DNA samples to nuclease cleavage was confirmed by the resulting in-cell NMR spectra. Modifying only the first phosphate group led to a slowdown of the degradation reaction, but did not prevent complete degradation of the samples. The ability to stabilize RNA was examined utilizing two procedures: the first employed phosphorothioate modification of the backbone, similar to the process that was used to decrease the degradation of the DNA samples; the second used substrates that had been modified by methylating the O2'-hydroxyl groups of the RNA. Both of these modifications were successful in extending the stability of the RNA samples.

Injecting synthetically prepared NAs proved to be fatal to the oocytes, likely due to low molecular weight impurities. This problem was overcome by butanol precipitating the NA preparations prior to microinjection. Analyses were performed to determine the extent of leakage from the cells. The potential for cell leakage is greater when using microinjection to introduce labeled target into the cell, due to the incision made during the injection. Results indicated that less than 5\% leakage from the oocytes is occurring. This confirms that almost all of the NA signals in the NMR spectra arise from endogenous NAs. Background signals presented little or no problem for unambiguously detecting aromatic, imino and amino resonances associated with the injected NAs. Spectra attributed to aliphatic/sugar regions $\mathrm{C} 2^{\prime}-\mathrm{H} 2^{\prime} / \mathrm{H} 2^{\prime \prime}$ and $\mathrm{C}^{\prime}-\mathrm{H}^{\prime} / \mathrm{H} 5^{\prime \prime}$ contained significant background signals and the $\mathrm{C} 3^{\prime}-\mathrm{H} 3^{\prime}$ region of the ${ }^{1} \mathrm{H}\left\{{ }^{13} \mathrm{C}\right\}$-HSQC spectra was dominated by a water suppression artifact. No oocyte background was observed for signals corresponding to the $\mathrm{C}^{\prime}{ }^{\prime}-\mathrm{H} 1^{\prime}$ and $\mathrm{C} 4^{\prime}-\mathrm{H} 4{ }^{\prime}$ regions.

Hansel et al. [85] also examined the feasibility of determining the conformation of injected NAs by studying a short fragment that is a constituent of telomeric DNA. Telomeric DNA forms quadruplex structures at the $3^{\prime}$ ends of chromosomes [88]. Quadruplex DNA is known to inhibit the activity of telomerase [89]. G-quadruplex conformations depend on specific counterions, molecular crowding and sequence composition [90-97]. Unlabeled 
$\mathrm{d}\left(\mathrm{G}_{3}\left(\mathrm{TTAG}_{3}\right)_{3} \mathrm{~T}\right)$ was injected into oocytes; this sequence was shown to take on a baskettype G-quadruplex [90,98-107] conformation in solutions containing potassium ions [108]. The resulting in-cell spectra were of low resolution and sufficiently different from those obtained in vitro so as to preclude a structural interpretation of the spectrum. The results further demonstrate that there are differences in conformation between in vitro and in-cell conditions.

The cost of preparing labeled NAs is high. However, it is possible to recover a large percentage of these NAs after use. The recovery process yield is as high as 70\% for the RNA hairpin. Alternatively, it may be possible to bypass the high cost of labeled NAs by working with unlabeled NAs: it was observed that background ${ }^{1} \mathrm{H}$ signals in the imino region of oocyte NMR spectra are considerably less than in other regions, resulting in the ability to observe some resonances of unlabeled NAs in the cellular environment.

3.4.2 Non-specific protein-DNA interactions-In E. coli, expression of the Met regulon is controlled by the transcriptional repressor metJ. The Met regulon is comprised of 7 sites located throughout the bacterial genome and contains at least twelve genes that code for proteins involved in the biosynthesis and transport of methionine $[109,110]$. Each gene carries 2-5 tandem repeats of the metJ binding site in their promoters called metboxes [111]. MetJ binds to the metboxes to repress [111-113] transcription within 30 minutes of a change in methionine concentration [114,115]. Augustus et al. [116] demonstrated through in-cell NMR experiments that metJ associates non-specifically with genomic DNA and postulated that these interactions provide a rapid mechanism for specific binding of metJ to metbox sequences to regulate methionine biosynthesis.

MetJ was uniformly $\left[U_{-}{ }^{15} \mathrm{~N}\right]$ labeled and overexpressed in bacteria. The resulting in-cell and lysed cell ${ }^{1} \mathrm{H}\left\{{ }^{15} \mathrm{~N}\right\}$-HSQC spectra contained only a few weak signals. Control experiments indicated that labeled metJ, partially purified from the lysates, was present in sufficient concentrations to produce a NMR spectrum comparable to that obtained for purified metJ in vitro. The absence of strong NMR peaks suggested that metJ was associating with large molecular species inside the cell that restricted its motion, rendering it invisible to NMR spectroscopy.

Since metJ is a DNA-binding protein and is present at a concentration that is several thousand-fold larger than the concentration of metbox sequences in the cell, non-specific binding to DNA was postulated as the reason that no NMR spectrum was obtained. To test this hypothesis, nonspecific (sonicated salmon sperm) DNA was titrated into a solution of uniformly labeled, purified $\left[U_{-}{ }^{15} \mathrm{~N}\right]$ metJ in vitro. The metJ peaks originally present in the NMR spectrum gradually broadened and ultimately disappeared as the concentration of DNA was increased. The progressive broadening, with no concomitant changes in chemical shifts, suggested that metJ bound nonspecifically to the DNA.

The metJ NMR spectrum was recovered using either of two methods: the first used DNase and $\mathrm{MgSO}_{4}$ to digest the DNA and release free metJ restoring the NMR signal; the second used a short oligonucleotide containing two metJ binding sequences to compete away the nonspecific DNA to yield an NMR spectrum of metJ bound to the oligonucleotide. Purified $\left[U-{ }^{15} \mathrm{~N}\right]$ metJ titrated with unlabeled cell lysate yielded results similar to those observed using labeled metJ over-expressed in whole cells and cell lysates.

The results indicate that metJ interacts extensively and non-specifically with genomic DNA inside bacterial cells. This observation is substantiated by the fact that metJ can locate a target sequence faster in the presence of longer pieces of DNA [117]. The ability of metJ to interact non-specifically with DNA, rather than relying on free diffusion, provides a 
mechanism to explain how metJ locates and binds with high specificity to metbox sequences in order to rapidly regulate methionine biosynthesis.

\section{Conclusions and future directions}

The application of in-cell NMR spectroscopy to cellular structural biology is still in its infancy. The first steps have been taken to demonstrate the feasibility of using in-cell NMR experiments to study proteins and nucleic acids, and their interactions in prokaryotic and eukaryotic cells. In-cell NMR spectroscopy continues to expand thanks to new procedures for introducing labeled proteins into living cells and advancements in instrumentation. Studies utilizing prokaryotic cells have become quite commonplace, whereas there are still some challenges, such as detecting labeled targets at physiological concentrations and signal broadening due to intracellular interactions, to be overcome before eukaryotic cells can be routinely used for in-cell NMR. Protein in-cell NMR has revealed how the cellular environment influences molecular structure and interactions that are at the core of metabolic and signal transduction pathways. Expanding in-cell NMR to study nucleic acid structure and dynamics will allow us to probe the central dogma of biology under physiological conditions with unprecedented resolution. Ongoing concerted efforts are still needed to realize this potential.

\section{Acknowledgments}

This work was supported by NIH R01 GM085006-01A2 grant and American Diabetes Association Career Development Award 1-06-CD-23 to A.S..

\section{Glossary of Abbreviations}

3FY
$\alpha-S Y N$
A-E
AUIM
BSA
CI2
CK2
CPP
CPP Tat
CYANA
DUB
ERK
FK506
FKBP
FRAP
FRB
FRET

3-fluoro-tyrosine

$\alpha$-synuclein

Di-peptide alanine-glutamic acid

28 amino acid peptide from ataxin 3

Bovine Serum Albumin

Chymotrypsin Inhibitor 2

Casein Kinase 2

Cell penetrating peptide

Cell penetrating peptide from the Tat Protein of HIV-1

Software package for structure calculation using torsion angle dynamics

Deubiquitinating enzymes

Extracellular signal-Regulated Kinase

Tacrolimus, an immunosuppressive drug

FK506 Binding Protein

Fluorescence Recovery After Photobleaching

FKBP-Rapamycin-Binding domain of mTOR

Fluorescence Resonance Energy Transfer 


\begin{tabular}{|c|c|}
\hline Fyn & Non-receptor tyrosine protein kinase \\
\hline GB1 & Streptococcal protein G B1 domain \\
\hline GFP & Green Fluorescence Protein \\
\hline Gsk3ß & Glycogen synthase kinase 3 \\
\hline HIV1-CPP ${ }_{\text {Tat }}$ & Cell penetrating peptide from the Tat Protein of HIV-1 \\
\hline HMQC & Heteronuclear Multiple Quantum Coherence \\
\hline HRS & Hepatocyte growth factor-regulated tyrosine kinase substrate \\
\hline HSQC & Heteronuclear Single Quantum Coherence \\
\hline HTS & High Throughput Screening \\
\hline IPTG & IsoPropyl 1-Thio- $\beta$-D-Galactopyranoside \\
\hline ITAM & Immunoreceptor Tyrosine-based Activation Motif \\
\hline Jak1 & Janus kinase 1 , non-receptor tyrosine protein kinase \\
\hline LB & Luria-Bertani medium \\
\hline M9 & Minimal growth medium \\
\hline MetJ & DNA-binding transcriptional repressor \\
\hline MHC & Major Histocompatibility Complex \\
\hline mTOR & Mammalian Target Of Rapamycin \\
\hline NA & Nucleic Acid \\
\hline NmerA & Metal binding domain of mercuric ion reductase \\
\hline NMR & Nuclear Magnetic Resonance \\
\hline NOE & Nuclear Overhauser Enhancement \\
\hline NOESY & Nuclear Overhauser Enhancement Spectroscopy \\
\hline PAGE & Polyacrylamide Gel Electrophoresis \\
\hline PDB & Protein Data Bank \\
\hline PKA & Protein Kinase A \\
\hline PTM & Post Translational Modifications \\
\hline PVP & Polyvinyl pyrrolidone \\
\hline SDS-PAGE & Sodium Dodecyl Sulfate Polyacrylamide Gel Electrophoresis \\
\hline SMILI-NMR & Screening Small Molecule Interactor Library using In-cell NMR \\
\hline SOFAST-HMQC & $\begin{array}{l}\text { band-Selective Optimized-Flip-Angle Short-Transient HMQC } \\
\text { spectra }\end{array}$ \\
\hline STAM2 & Signal-Transducing Adapter Molecule 2 \\
\hline STINT-NMR & In-cell NMR-based method for mapping the STructural INTeractions \\
\hline SV40 & Simian virus 40 \\
\hline Tat & HIV gene Trans-Activator of Transcription \\
\hline tmfF & Trifluoromethyl-L-phenylalanine \\
\hline
\end{tabular}


TOCSY

TROSY-HSQC

TTHA1718

Ub

Ub-3A

Ub-3A-CPP ${ }_{\text {Tat }}$

Ub-D77

UCH

UIM

UIP

VHS

$\mathrm{XT}_{111-132}$
Total Correlation Spectroscopy

Transverse optimized spectroscopy

Putative heavy-metal bonding protein from T. thermophilus

Ubiquitin

Ubiquitin mutated at three sites (L8A, I44A, V70A)

Ubiquitin $3 \mathrm{~A}$ with $\mathrm{C}$-terminal $\mathrm{CPP}_{\text {Tat }}$ fusion

Ubiquitin containing a C-terminal D77 residue

Ubiquitin C-terminal Hydrolase

Ubiquitin Interacting Motif

Ubiquitin Interacting Proteins

Vps-27, Hrs and STAM domain

Regulatory region of the viral SV40 large T antigen

\section{References}

1. Sali A, Glaeser R, Earnest T, Baumeister W. From words to literature in structural proteomics. Nature. 2003; 422:216-225. [PubMed: 12634795]

2. Uetz P, Giot L, Cagney G, Mansfield TA, Judson RS, Knight JR, Lockshon D, Narayan V, Srinivasan M, Pochart P, Qureshi-Emili A, Li Y, Godwin B, Conover D, Kalbfleisch T, Vijayadamodar G, Yang M, Johnston M, Fields S, Rothberg JM. A comprehensive analysis of protein-protein interactions in Saccharomyces cerevisiae. Nature. 2000; 403:623-627. [PubMed: 10688190]

3. Rain JC, Selig L, De Reuse H, Battaglia V, Reverdy C, Simon S, Lenzen G, Petel F, Wojcik J, Schachter V, Chemama Y, Labigne A, Legrain P. The protein-protein interaction map of Helicobacter pylori. Nature. 2001; 409:211-215. [PubMed: 11196647]

4. Serber Z, Dotsch V. In-cell NMR spectroscopy. Biochemistry. 2001; 40:14317-14323. [PubMed: 11724542]

5. Almeida MS, Peti W, Wuthrich K. ${ }^{1} \mathrm{H}-,{ }^{13} \mathrm{C}$ - and ${ }^{15} \mathrm{~N}-\mathrm{NMR}$ assignment of the conserved hypothetical protein TM0487 from Thermotoga maritima. J. Biomol. NMR. 2004; 29:453-454. [PubMed: 15213465]

6. Waugh DS. Genetic tools for selective labeling of proteins with alpha- ${ }^{15} \mathrm{~N}$-amino acids. J. Biomol. NMR. 1996; 8:184-192. [PubMed: 8914274]

7. McIntosh LP, Dahlquist FW. Biosynthetic incorporation of ${ }^{15} \mathrm{~N}$ and ${ }^{13} \mathrm{C}$ for assignment and interpretation of nuclear magnetic resonance spectra of proteins. Q. Rev. Biophys. 1990; 23:1-38. [PubMed: 2188278]

8. Serber Z, Straub W, Corsini L, Nomura AM, Shimba N, Craik CS, Ortiz de Montellano P, Dotsch V. Methyl groups as probes for proteins and complexes in in-cell NMR experiments. J. Am. Chem. Soc. 2004; 126:7119-7125. [PubMed: 15174883]

9. Rosen MK, Gardner KH, Willis RC, Parris WE, Pawson T, Kay LE. Selective methyl protonation of perdeuterated proteins. J. Mol. Biol. 1996; 263:627-636. [PubMed: 8947563]

10. Cheng H, Westler WM, Xie B, Oh BH, Markley JL. Protein expression selective isotopic labeling, and analysis of hyperfine-shifted NMR signals of Anabaena 7120 vegetative [2Fe-2S]ferredoxin. Arch. Biochem. Biophys. 1995; 316:619-634. [PubMed: 7840674]

11. Wang GF, Li C, Pielak GJ. ${ }^{19}$ F NMR studies of alpha-synuclein-membrane interactions. Protein Sci. 2010; 19:1686-1691. [PubMed: 20629174]

12. Hammill JT, Miyake-Stoner S, Hazen JL, Jackson JC, Mehl RA. Preparation of site-specifically labeled fluorinated proteins for ${ }^{19}$ F-NMR structural characterization. Nat. Protoc. 2007; 2:26012607. [PubMed: 17948003] 
13. Guzman LM, Barondess JJ, Beckwith J. FtsL, an essential cytoplasmic membrane protein involved in cell division in Escherichia coli. J. Bacteriol. 1992; 174:7716-7728. [PubMed: 1332942]

14. Haldimann A, Daniels LL, Wanner BL. Use of new methods for construction of tightly regulated arabinose and rhamnose promoter fusions in studies of the Escherichia coli phosphate regulon. J. Bacteriol. 1998; 180:1277-1286. [PubMed: 9495769]

15. Selenko P, Serber Z, Gadea B, Ruderman J, Wagner G. Quantitative NMR analysis of the protein G B1 domain in Xenopus laevis egg extracts and intact oocytes. Proc. Natl. Acad. Sci. USA. 2006; 103:11904-11909. [PubMed: 16873549]

16. Gronenborn AM, Filpula DR, Essig NZ, Achari A, Whitlow M, Wingfield PT, Clore GM. A novel, highly stable fold of the immunoglobulin binding domain of streptococcal protein G. Science. 1991; 253:657-661. [PubMed: 1871600]

17. Schnizler K, Kuster M, Methfessel C, Fejtl M. The Roboocyte: Automated cDNA/mRNA injection and subsequent TEVC recording on Xenopus Oocytes in 96-well microtiter plates. Receptors Channels. 2003; 9:41-48. [PubMed: 12825297]

18. Bodart JF, Wieruszeski JM, Amniai L, Leroy A, Landrieu I, Rousseau-Lescuyer A, Vilain JP, Lippens G. NMR observation of Tau in Xenopus oocytes. J. Magn. Reson. 2008; 192:252-257. [PubMed: 18378475]

19. Gard DL, Kirschner MW. Microtubule assembly in cytoplasmic extracts of Xenopus oocytes and eggs. J. Cell. Biol. 1987; 105:2191-2201. [PubMed: 3680377]

20. Lippens G, Wieruszeski JM, Leroy A, Smet C, Sillen A, Buee L, Landrieu I. Proline-directed random-coil chemical shift values as a tool for the NMR assignment of the tau phosphorylation sites. Chembiochem. 2004; 5:73-78. [PubMed: 14695515]

21. Smet C, Leroy A, Sillen A, Wieruszeski JM, Landrieu I, Lippens G. Accepting its random coil nature allows a partial NMR assignment of the neuronal Tau protein. Chembiochem. 2004; 5:1639-1646. [PubMed: 15532033]

22. Sillen A, Barbier P, Landrieu I, Lefebvre S, Wieruszeski JM, Leroy A, Peyrot V, Lippens G. NMR investigation of the interaction between the neuronal protein tau and the microtubules. Biochemistry. 2007; 46:3055-3064. [PubMed: 17311412]

23. Inomata K, Ohno A, Tochio H, Isogai S, Tenno T, Nakase I, Takeuchi T, Futaki S, Ito Y, Hiroaki H, Shirakawa M. High-resolution multi-dimensional NMR spectroscopy of proteins in human cells. Nature. 2009; 458:106-109. [PubMed: 19262675]

24. Futaki S. Oligoarginine vectors for intracellular delivery: design and cellular-uptake mechanisms. Biopolymers. 2006; 84:241-249. [PubMed: 16333858]

25. Nakase I, Takeuchi T, Tanaka G, Futaki S. Methodological and cellular aspects that govern the internalization mechanisms of arginine-rich cell-penetrating peptides. Adv. Drug. Deliv. Rev. 2008; 60:598-607. [PubMed: 18045727]

26. Wender PA, Galliher WC, Goun EA, Jones LR, Pillow TH. The design of guanidinium-rich transporters and their internalization mechanisms. Adv. Drug. Deliv. Rev. 2008; 60:452-472. [PubMed: 18164781]

27. Schwarze SR, Ho A, Vocero-Akbani A, Dowdy SF. In vivo protein transduction: delivery of a biologically active protein into the mouse. Science. 1999; 285:1569-1572. [PubMed: 10477521]

28. Takeuchi T, Kosuge M, Tadokoro A, Sugiura Y, Nishi M, Kawata M, Sakai N, Matile S, Futaki S. Direct and rapid cytosolic delivery using cell-penetrating peptides mediated by pyrenebutyrate. ACS Chem. Biol. 2006; 1:299-303. [PubMed: 17163758]

29. Hicke L, Schubert HL, Hill CP. Ubiquitin-binding domains. Nat. Rev. Mol. Cell. Biol. 2005; 6:610-621. [PubMed: 16064137]

30. Loison F, Nizard P, Sourisseau T, Le Goff P, Debure L, Le Drean Y, Michel D. A ubiquitin-based assay for the cytosolic uptake of protein transduction domains. Mol. Ther. 2005; 11:205-214. [PubMed: 15668132]

31. Sakai T, Tochio H, Tenno T, Ito Y, Kokubo T, Hiroaki H, Shirakawa M. In-cell NMR spectroscopy of proteins inside Xenopus laevis oocytes. J. Biomol. NMR. 2006; 36:179-188. [PubMed: 17031531]

32. Giriat I, Muir TW. Protein semi-synthesis in living cells. J. Am. Chem. Soc. 2003; 125:7180-7181. [PubMed: 12797783] 
33. Tompa, P. Structure and fuction of intrinsically disordered proteins. CRC Press; 2010. p. 92-95.

34. Creighton TE, Chothia C. Protein structure. Selecting buried residues. Nature. 1989; 339:14-15. [PubMed: 2716825]

35. Rosen MK, Gardner KH, Willis RC, Parris WE, Pawson T, Kay LE. Selective methyl group protonation of perdeuterated proteins. J. Mol. Biol. 1996; 263:627-636. [PubMed: 8947563]

36. Slade KM, Baker R, Chua M, Thompson NL, Pielak GJ. Effects of recombinant protein expression on green fluorescent protein diffusion in Escherichia coli. Biochemistry. 2009; 48:5083-5089. [PubMed: 19413350]

37. Cruzeiro-Silva C, Albernaz FP, Valente AP, Almeida FC. In-Cell NMR spectroscopy: inhibition of autologous protein expression reduces Escherichia coli lysis. Cell. Biochem. Biophys. 2006; 44:497-502. [PubMed: 16679537]

38. Li C, Charlton LM, Lakkavaram A, Seagle C, Wang G, Young GB, Macdonald JM, Pielak GJ. Differential dynamical effects of macromolecular crowding on an intrinsically disordered protein and a globular protein: implications for in-cell NMR spectroscopy. J. Am. Chem. Soc. 2008; 130:6310-6311. [PubMed: 18419123]

39. Richter HP, Hoock C, Neumcke B. Morphological and electrophysiological properties of centrifuged stratified Xenopus oocytes. Biol. Cell. 1995; 84:129-138. [PubMed: 8720433]

40. Maniatis, T.; Fritsch, EF.; Sambrook, J. Molecular cloning : a laboratory manual. Cold Spring Harbor Laboratory; Cold Spring Harbor, N.Y.: 1982.

41. Kühtreiber, WM.; Lanza, RP.; Chick, WL. Cell encapsulation technology and therapeutics. Birkhauser; Boston: 1999.

42. Li C, Wang Y, Pielak GJ. Translational and rotational diffusion of a small globular protein under crowded conditions. J. Phys. Chem. B. 2009; 113:13390-13392. [PubMed: 19791823]

43. Ferrage F, Zoonens M, Warschawski DE, Popot JL, Bodenhausen G. Slow diffusion of macromolecular assemblies by a new pulsed field gradient NMR method. J. Am. Chem. Soc. 2003; 125:2541-2545. [PubMed: 12603142]

44. Kay LE, Torchia DA, Bax A. Backbone dynamics of proteins as studied by ${ }^{15} \mathrm{~N}$ inverse detected heteronuclear NMR spectroscopy: application to staphylococcal nuclease. Biochemistry. 1989; 28:8972-8979. [PubMed: 2690953]

45. Cantor, CR.; Schimmel, PR. Biophysical Chemistry Part II: Techniques for the study of biological structure and function. W.H Freeman and Company; New York: 1980.

46. Sakakibara D, Sasaki A, Ikeya T, Hamatsu J, Hanashima T, Mishima M, Yoshimasu M, Hayashi N, Mikawa T, Walchli M, Smith BO, Shirakawa M, Guntert P, Ito Y. Protein structure determination in living cells by in-cell NMR spectroscopy. Nature. 2009; 458:102-105. [PubMed: 19262674]

47. Laue ED, Skilling J, Staunton J. Maximum entropy reconstruction of spectra containing antiphase peaks. J. Magn. Reson. 1985; 63:418-424.

48. Laue ED, Mayger MR, Skilling J, Staunton J. Reconstruction of phase sensitive 2D NMR spectra by maximum entropy. J. Magn. Reson. 1986; 68:14-29.

49. Guntert P, Mumenthaler C, Wuthrich K. Torsion angle dynamics for NMR structure calculation with the new program DYANA. J. Mol. Biol. 1997; 273:283-298. [PubMed: 9367762]

50. Livingston DJ, Mar GNL, Brown WD. Myoglobin diffusion in bovine heart muscle. Science. 1983; 220:71-73. [PubMed: 6828881]

51. Burz DS, Dutta K, Cowburn D, Shekhtman A. Mapping structural interactions using in-cell NMR spectroscopy (STINT-NMR). Nat. Methods. 2006; 3:91-93. [PubMed: 16432517]

52. Burz DS, Dutta K, Cowburn D, Shekhtman A. In-cell NMR for protein-protein interactions (STINT-NMR). Nat. Protoc. 2006; 1:146-152. [PubMed: 17406226]

53. Lutz R, Bujard H. Independent and tight regulation of transcriptional units in Escherichia coli via the LacR/O, the TetR/O and AraC/I1-I2 regulatory elements. Nucleic Acids Res. 1997; 25:12031210. [PubMed: 9092630]

54. Di Fiore PP, Polo S, Hofmann K. When ubiquitin meets ubiquitin receptors: a signalling connection. Nat. Rev. Mol. Cell Biol. 2003; 4:491-497. [PubMed: 12778128] 
55. Bache KG, Raiborg C, Mehlum A, Stenmark H. STAM and HRS are subunits of a multivalent ubiquitin-binding complex on early endosomes. J. Biol. Chem. 2003; 278:12513-12521. [PubMed: 12551915]

56. Shekhtman A, Cowburn D. A ubiquitin-interacting motif from Hrs binds to and occludes the ubiquitin surface necessary for polyubiquitination in monoubiquitinated proteins. Biochemical and Biophysical Research Communications. 2002; 296:1222-1227. [PubMed: 12207904]

57. Mizuno E, Kawahata K, Kato M, Kitamura N, Komada M. STAM proteins bind ubiquitinated proteins on the early endosome via the VHS domain and ubiquitin-interacting motif. Mol. Biol. Cell. 2003; 14:3675-3689. [PubMed: 12972556]

58. Xie J, Thapa R, Reverdatto S, Burz DS, Shekhtman A. Screening of small molecule interactor library by using in-cell NMR spectroscopy (SMILI-NMR). J. Med. Chem. 2009; 52:3516-3522. [PubMed: 19422228]

59. Harding MW, Galat A, Uehling DE, Schreiber SL. A receptor for the immunosuppressant FK506 is a cis-trans peptidyl-prolyl isomerase. Nature. 1989; 341:758-760. [PubMed: 2477715]

60. Dudkin L, Dilling MB, Cheshire PJ, Harwood FC, Hollingshead M, Arbuck SG, Travis R, Sausville EA, Houghton PJ. Biochemical correlates of mTOR inhibition by the rapamycin ester CCI-779 and tumor growth inhibition. Clin. Cancer Res. 2001; 7:1758-1764. [PubMed: 11410517]

61. Vogt PK. PI 3-kinase, mTOR, protein synthesis and cancer. Trends Mol. Med. 2001; 7:482-484. [PubMed: 11689313]

62. Horwell DC, Howson W, Ratcliffe GS, Rees DC. The design of a dipeptide library for screening at peptide receptor sites. Bioorg. Med. Chem. Lett. 1993; 3:799-702.

63. Horwell DC, Hughes J, Hunter JC, Pritchard MC, Richardson RS, Roberts E, Woodruff GN. Rationally designed "dipeptoid" analogues of CCK. alpha-Methyltryptophan derivatives as highly selective and orally active gastrin and CCK-B antagonists with potent anxiolytic properties. J. Med. Chem. 1991; 34:404-414. [PubMed: 1671419]

64. Boden P, Eden JM, Hodgson J, Horwell DC, Hughes J, McKnight AT, Lewthwaite RA, Pritchard MC, Raphy J, Meecham K, Ratcliffe GS, Suman-Chauhan N, Woodruff GN. Use of a dipeptide chemical library in the development of non-peptide tachykinin NK3 receptor selective antagonists. J. Med. Chem. 1996; 39:1664-1675. [PubMed: 8648606]

65. Ondetti MA, Rubin B, Cushman DW. Design of specific inhibitors of angiotensin-converting enzyme: new class of orally active antihypertensive agents. Science. 1977; 196:441-444. [PubMed: 191908]

66. Olson ER, Dunyak DS, Jurss LM, Poorman RA. Identification and characterization of dppA, an Escherichia coli gene encoding a periplasmic dipeptide transport protein. J. Bacteriol. 1991; 173:234-244. [PubMed: 1702779]

67. Saito H, Inui K. Dipeptide transporters in apical and basolateral membranes of the human intestinal cell line Caco-2. Am. J. Physiol. 1993; 265:G289-294. [PubMed: 8396335]

68. Tenno T, Fujiwara K, Tochio H, Iwai K, Morita EH, Hayashi H, Murata S, Hiroaki H, Sato M, Tanaka K, Shirakawa M. Structural basis for distinct roles of Lys63- and Lys48-linked polyubiquitin chains. Genes Cells. 2004; 9:865-875. [PubMed: 15461659]

69. Johnston SC, Riddle SM, Cohen RE, Hill CP. Structural basis for the specificity of ubiquitin Cterminal hydrolases. EMBO J. 1999; 18:3877-3887. [PubMed: 10406793]

70. Zhang M, Yuan T. Molecular mechanisms of calmodulin's functional versatility. Biochem. Cell. Biol. 1998; 76:313-323. [PubMed: 9923700]

71. Delobel P, Flament S, Hamdane M, Delacourte A, Vilain JP, Buee L. Modelling Alzheimerspecific abnormal Tau phosphorylation independently of GSK3beta and PKA kinase activities. FEBS Lett. 2002; 516:151-155. [PubMed: 11959122]

72. Landrieu I, Lacosse L, Leroy A, Wieruszeski JM, Trivelli X, Sillen A, Sibille N, Schwalbe H, Saxena K, Langer T, Lippens G. NMR analysis of a Tau phosphorylation pattern. J. Am. Chem. Soc. 2006; 128:3575-3583. [PubMed: 16536530]

73. Sarkissian M, Mendez R, Richter JD. Progesterone and insulin stimulation of CPEB-dependent polyadenylation is regulated by Aurora A and glycogen synthase kinase-3. Genes Dev. 2004; 18:48-61. [PubMed: 14724178] 
74. Selenko P, Frueh DP, Elsaesser SJ, Haas W, Gygi SP, Wagner G. In situ observation of protein phosphorylation by high-resolution NMR spectroscopy. Nat. Struct. Mol. Biol. 2008; 15:321-329. [PubMed: 18297086]

75. Zhou P, Lugovsky AA. A solubility-enhancement tag (SET) for NMR studies of poorly behaving proteins. J. Biomol. NMR. 2001; 20:11-14. [PubMed: 11430750]

76. Hubner S, Xiao CY, Jans DA. The protein kinase CK2 site (Ser111/112) enhances recognition of the simian virus 40 large T-antigen nuclear localization sequence by importin. J. Biol. Chem. 1997; 272:17191-17195. [PubMed: 9202041]

77. Rihs HP, Jans DA, Fan H, Peters R. The rate of nuclear cytoplasmic protein transport is determined by the casein kinase II site flanking the nuclear localization sequence of the SV40 T-antigen. EMBO J. 1991; 10:633-639. [PubMed: 1848177]

78. Bienkiewicz EA, Lumb KJ. Random-coil chemical shifts of phosphorylated amino acids. J. Biomol. NMR. 1999; 15:203-206. [PubMed: 10677823]

79. Murray AW. Cell cycle extracts. Methods Cell. Biol. 1991; 36:581-605. [PubMed: 1839804]

80. Wilhelm V, Rojas P, Gatica M, Allende CC, Allende JE. Expression of the subunits of protein kinase CK2 during oogenesis in Xenopus laevis. Eur. J. Biochem. 1995; 232:671-676. [PubMed: 7556222]

81. Burz DS, Shekhtman A. In-cell biochemistry using NMR spectroscopy. PLoS One. 2008; 3:e2571. [PubMed: 18626516]

82. Polo S, Sigismund S, Faretta M, Guidi M, Capua MR, Bossi G, Chen H, De Camilli P, Di Fiore PP. A single motif responsible for ubiquitin recognition and monoubiquitination in endocytic proteins. Nature. 2002; 416:451-455. [PubMed: 11919637]

83. Hicke L, Riezman H. Ubiquitination of a yeast plasma membrane receptor signals its ligandstimulated endocytosis. Cell. 1996; 84:277-287. [PubMed: 8565073]

84. Pandey A, Fernandez MM, Steen H, Blagoev B, Nielsen MM, Roche S, Mann M, Lodish HF. Identification of a novel immunoreceptor tyrosine-based activation motif-containing molecule, STAM2, by mass spectrometry and its involvement in growth factor and cytokine receptor signaling pathways. J. Biol. Chem. 2000; 275:38633-38639. [PubMed: 10993906]

85. Hansel R, Foldynova-Trantirkova S, Lohr F, Buck J, Bongartz E, Bamberg E, Schwalbe H, Dotsch $\mathrm{V}$, Trantirek L. Evaluation of parameters critical for observing nucleic acids inside living Xenopus laevis oocytes by in-cell NMR spectroscopy. J. Am. Chem. Soc. 2009; 131:15761-15768. [PubMed: 19824671]

86. Duchardt E, Schwalbe H. Residue specific ribose and nucleobase dynamics of the cUUCGg RNA tetraloop motif by NMR ${ }^{13} \mathrm{C}$ relaxation. J. Biomol. NMR. 2005; 32:295-308. [PubMed: 16211483]

87. Ferner J, Villa A, Duchardt E, Widjajakusuma E, Wohnert J, Stock G, Schwalbe H. NMR and MD studies of the temperature-dependent dynamics of RNA YNMG-tetraloops. Nucleic Acids Res. 2008; 36:1928-1940. [PubMed: 18272534]

88. Makarov VL, Hirose Y, Langmore JP. Long G tails at both ends of human chromosomes suggest a $\mathrm{C}$ strand degradation mechanism for telomere shortening. Cell. 1997; 88:657-666. [PubMed: 9054505]

89. Zahler AM, Williamson JR, Cech TR, Prescott DM. Inhibition of telomerase by G-quartet DNA structures. Nature. 1991; 350:718-720. [PubMed: 2023635]

90. Qin Y, Hurley LH. Structures, folding patterns, and functions of intramolecular DNA Gquadruplexes found in eukaryotic promoter regions. Biochimie. 2008; 90:1149-1171. [PubMed: 18355457]

91. Dai J, Carver M, Yang D. Polymorphism of human telomeric quadruplex structures. Biochimie. 2008; 90:1172-1183. [PubMed: 18373984]

92. Inoue M, Miyoshi D, Sugimoto N. Structural switch of telomere DNA by $\mathrm{pH}$ and monovalent cation. Nucleic Acids Symp. Ser. (Oxford). 2005:243-244.

93. Kypr J, Kejnovska I, Renciuk D, Vorlickova M. Circular dichroism and conformational polymorphism of DNA. Nucleic Acids Res. 2009; 37:1713-1725. [PubMed: 19190094] 
94. Miyoshi D, Matsumura S, Li W, Sugimoto N. Structural polymorphism of telomeric DNA regulated by $\mathrm{pH}$ and divalent cation. Nucleosides Nucleotides and Nucleic Acids. 2003; 22:203221.

95. Miyoshi D, Nakao A, Sugimoto N. Structural transition of d(G4T4G4) from antiparallel to parallel G-quartet induced by divalent cations. Nucleic Acids Res. Suppl. 2001:259-260. [PubMed: 12836363]

96. Miyoshi D, Nakao A, Sugimoto N. Molecular crowding regulates the structural switch of the DNA G-quadruplex. Biochemistry. 2002; 41:15017-15024. [PubMed: 12475251]

97. Miyoshi D, Nakao A, Sugimoto N. Structural transition from antiparallel to parallel G-quadruplex of d(G4T4G4) induced by $\mathrm{Ca}^{2+}$ Nucleic Acids Res. 2003; 31:1156-1163. [PubMed: 12582234]

98. Gatto B, Palumbo M, Sissi C. Nucleic acid aptamers based on the G-quadruplex structure: therapeutic and diagnostic potential. Curr. Med. Chem. 2009; 16:1248-1265. [PubMed: 19355883]

99. Huppert JL. Four-stranded nucleic acids: structure, function and targeting of G-quadruplexes. Chem. Soc. Rev. 2008; 37:1375-1384. [PubMed: 18568163]

100. Huppert JL. Hunting G-quadruplexes. Biochimie. 2008; 90:1140-1148. [PubMed: 18294969]

101. Huppert JL, Balasubramanian S. Prevalence of quadruplexes in the human genome. Nucleic Acids Res. 2005; 33:2908-2916. [PubMed: 15914667]

102. Huppert JL, Balasubramanian S. G-quadruplexes in promoters throughout the human genome. Nucleic Acids Res. 2007; 35:406-413. [PubMed: 17169996]

103. Lipps HJ, Rhodes D. G-quadruplex structures: in vivo evidence and function. Trends Cell. Biol. 2009; 19:414-422. [PubMed: 19589679]

104. Neidle S, Parkinson GN. Quadruplex DNA crystal structures and drug design. Biochimie. 2008; 90:1184-1196. [PubMed: 18395014]

105. Ou TM, Lu YJ, Tan JH, Huang ZS, Wong KY, Gu LQ. G-quadruplexes: targets in anticancer drug design. ChemMedChem. 2008; 3:690-713. [PubMed: 18236491]

106. Phan AT, Kuryavyi V, Patel DJ. DNA architecture: from G to Z. Curr. Opin. Struct. Biol. 2006; 16:288-298. [PubMed: 16714104]

107. Wong HM, Payet L, Huppert JL. Function and targeting of G-quadruplexes. Curr. Opin. Mol. Ther. 2009; 11:146-155. [PubMed: 19330720]

108. Lim KW, Amrane S, Bouaziz S, Xu W, Mu Y, Patel DJ, Luu KN, Phan AT. Structure of the human telomere in $\mathrm{K}^{+}$solution: a stable basket-type G-quadruplex with only two G-tetrad layers. J. Am. Chem. Soc. 2009; 131:4301-4309. [PubMed: 19271707]

109. Old IG, Phillips SE, Stockley PG. I. Saint Girons, Regulation of methionine biosynthesis in the Enterobacteriaceae. Prog. Biophys. Mol. Biol. 1991; 56:145-185. [PubMed: 1771231]

110. Gal J, Szvetnik A, Schnell R, Kalman M. The metD D-methionine transporter locus of Escherichia coli is an ABC transporter gene cluster. J. Bacteriol. 2002; 184:4930-4932. [PubMed: 12169620]

111. Belfaiza J, Parsot C, Martel A, de la Tour CB, Margarita D, Cohen GN, Saint-Girons I. Evolution in biosynthetic pathways: two enzymes catalyzing consecutive steps in methionine biosynthesis originate from a common ancestor and possess a similar regulatory region. Proc. Natl. Acad. Sci. USA. 1986; 83:867-871. [PubMed: 3513164]

112. Saint-Girons I, Belfaiza J, Guillou Y, Perrin D, Guiso N, Barzu O, Cohen GN. Interactions of the Escherichia coli methionine repressor with the metF operator and with its corepressor, Sadenosylmethionine. J. Biol. Chem. 1986; 261:10936-10940. [PubMed: 3090041]

113. Shoeman R, Redfield B, Coleman T, Greene RC, Smith AA, Brot N, Weissbach H. Regulation of methionine synthesis in Escherichia coli: Effect of metJ gene product and S-adenosylmethionine on the expression of the metF gene. Proc. Natl. Acad. Sci. USA. 1985; 82:3601-3605. [PubMed: 16593564]

114. Emmett MR, Johnson JR. Control of metF gene expression in maxicell preparations of Escherichia coli K-12: reversible action of the metJ protein and effect of vitamin B12. J. Bacteriol. 1986; 168:1491-1494. [PubMed: 3536888]

115. Collier CD, Johnson JR. The Escherichia coli K-12 metJ193 allele contains a point mutation which alters the hydrophobic pocket responsible for in vitro binding of S-adenosylmethionine: 
effects on cell growth and induction of met regulon expression. J. Bacteriol. 1990; 172:39183924. [PubMed: 2141834]

116. Augustus AM, Reardon PN, Spicer LD. MetJ repressor interactions with DNA probed by in-cell NMR. Proc. Natl. Acad. Sci. USA. 2009; 106:5065-5069. [PubMed: 19289840]

117. Lawrenson ID, Stockley PG. Kinetic analysis of operator binding by the E. coli methionine repressor highlights the role(s) of electrostatic interactions. FEBS Lett. 2004; 564:136-142. [PubMed: 15094055] 
a.

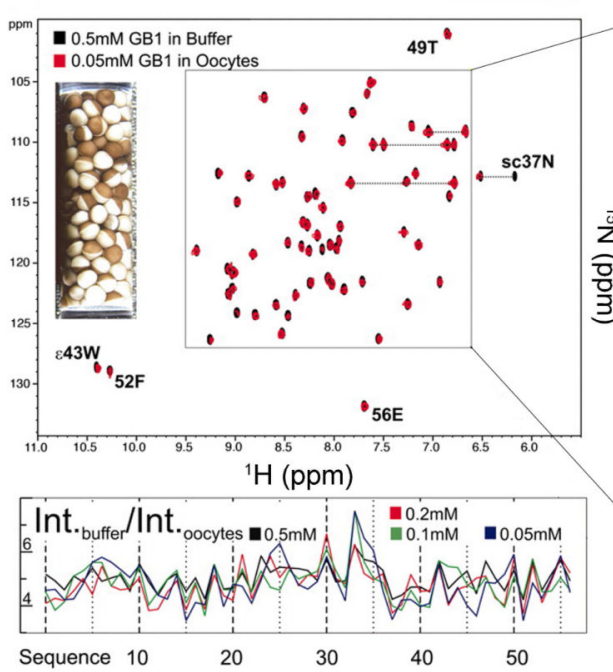

b.

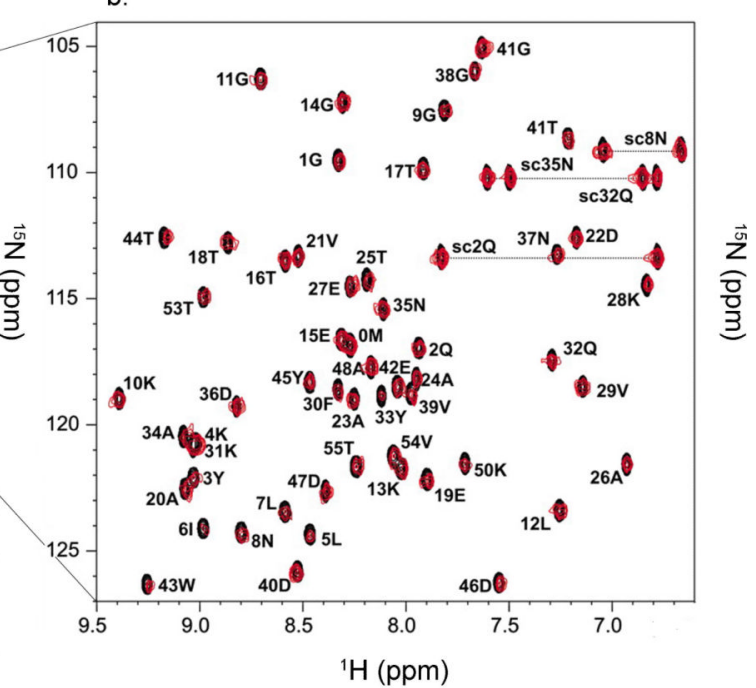

Figure 1.

GB1 in Xenopus oocytes. (a) (Left) Typical in-cell NMR sample of 200 oocytes in a Shigemi NMR tube. (Right) Overlay of the $2 \mathrm{D}{ }^{1} \mathrm{H}\left\{{ }^{15} \mathrm{~N}\right\}$-HSQC spectra of purified GB1 (0.5 $\mathrm{mM}$, black) and of GB1 in Xenopus oocytes (50 mM intracellular concentration, red). NMR spectra were acquired at $295 \mathrm{~K}$. The graph at the bottom left depicts intensity ratios (buffer over oocytes) for all GB1 residues at the indicated sample concentrations. (b) Expanded view of the spectra shown in (a). Reproduced from Selenko et al. [15]. 


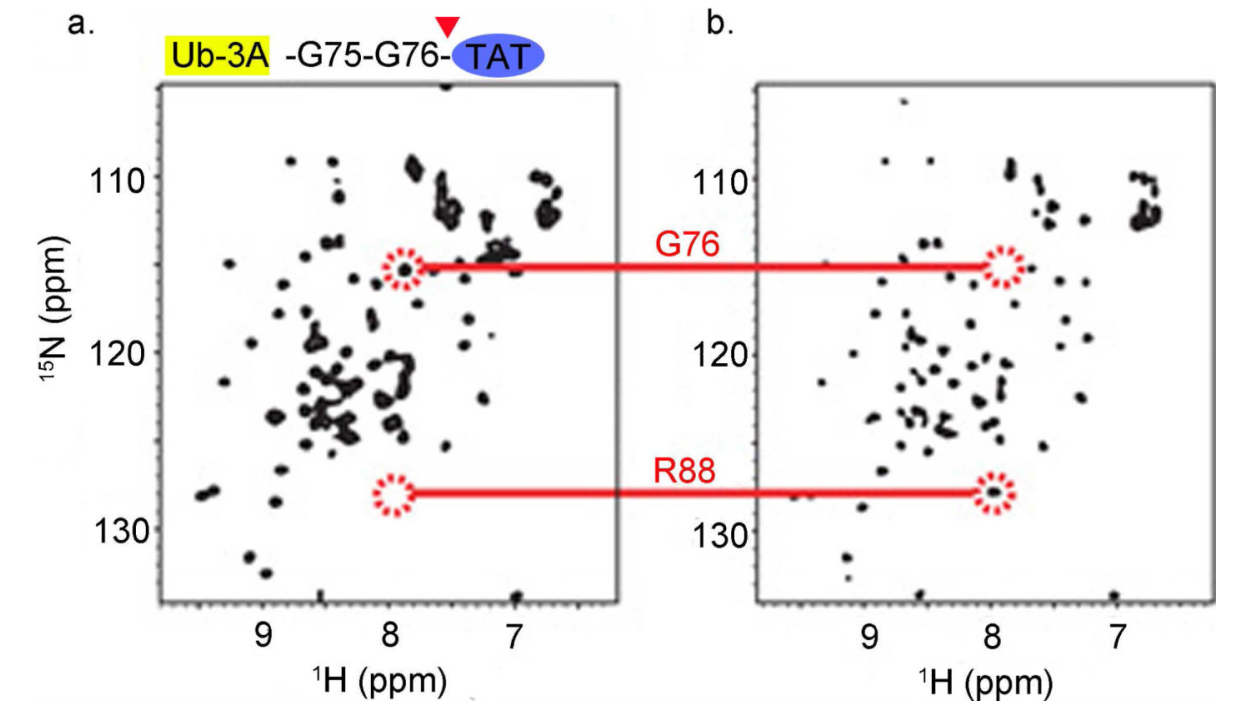
b.

Figure 2.

Ubiquitin in HeLa cells. (a) In-cell ${ }^{1} \mathrm{H}\left\{{ }^{15} \mathrm{~N}\right\}$-HSQC spectrum of Ub-3A. The C-terminal G76 is indicated. (b) In vitro reference spectrum of $\left[U_{-}{ }^{15} \mathrm{~N}\right] \mathrm{Ub}-3 \mathrm{~A}-\mathrm{CPP} \mathrm{Tat}_{\mathrm{Ta}}$ fusion protein. The C-terminal R88 at the end of $\mathrm{CPP}_{\text {Tat }}$ is indicated. NMR spectra were acquired at $295 \mathrm{~K}$. Reproduced from Inomata et al. [23]. 


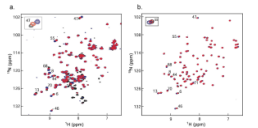

Figure 3.

Ubiquitin-ligand complexes in E. coli. (a) Overlay of ${ }^{1} \mathrm{H}\left\{{ }^{15} \mathrm{~N}\right\}-\mathrm{HSQC}$ spectra of $E$. coli after 3 hour over-expression of $\left[U_{-}{ }^{15} \mathrm{~N}\right]$ ubiquitin and $0 \mathrm{~h}$ (black), $2 \mathrm{~h}$ (red) and $3 \mathrm{~h}$ (blue) over-expression of AUIM. Individual peaks exhibiting large chemical shifts are labeled with corresponding assignments. (b) Overlay of ${ }^{1} \mathrm{H}\left\{{ }^{15} \mathrm{~N}\right\}$-HSQC spectra of free $\left[U_{-}{ }^{15} \mathrm{~N}\right]$ ubiquitin (black) and $\left[U_{-}{ }^{15} \mathrm{~N}\right]$ ubiquitin-AUIM complexes at a molar ratio of $1: 1$ (red) and 1:2 (blue). NMR spectra were acquired at $298 \mathrm{~K}$. Reproduced from Burz et al. [51,52]. 


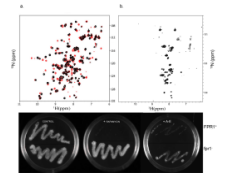

Figure 4.

(Top) Ternary FKBP-FRB-ligand complexes in E. coli.. (a) Overlay of ${ }^{1} \mathrm{H}\left\{{ }^{15} \mathrm{~N}\right\}$-HSQC spectra of $E$. coli after $4 \mathrm{~h}$ of over-expression of $\left[U_{-}{ }^{15} \mathrm{~N}\right]-\mathrm{FKBP}$ and $4 \mathrm{~h}$ sequential overexpression of FRB in the absence (black) and presence (red) of $150 \mu \mathrm{M}$ rapamycin.

(b) ${ }^{1} \mathrm{H}\left\{{ }^{15} \mathrm{~N}\right\}$-HSQC spectrum of $E$. coli after $4 \mathrm{~h}$ of over-expression of $\left[U-{ }^{15} \mathrm{~N}\right]-\mathrm{FKBP}$ and 4 $\mathrm{h}$ sequential over-expression of FRB in the presence (red) of $5 \mathrm{mM}$ A-E. NMR spectra were acquired at $295 \mathrm{~K}$.

(Bottom) Yeast assay for biological activity of the dipeptide, A-E. Isogenic haploid yeast strains $(S$. cerevisiae $)$ that express $\left(F P R 1^{+}\right)$or lack $\left(\right.$frpl $\left.1^{-}\right)$the FKBP proline isomerase were grown for 3 days on YPD medium. (c) Control plate. (d) $100 \mu \mathrm{M}$ rapamycin. Expression of FKBP allows the formation of a toxic FKBP-rapamycin-FRB bio-complex. (e) $5 \mathrm{mM}$ A-E.

Results indicate that the dipeptide induces formation of a bio-complex similar to that induced by rapamycin. The reduced growth in the $f r p 1^{-}$strain likely reflects the weaker affinity of A-E for FKBP. Reproduced from Xie et al. [58]. 


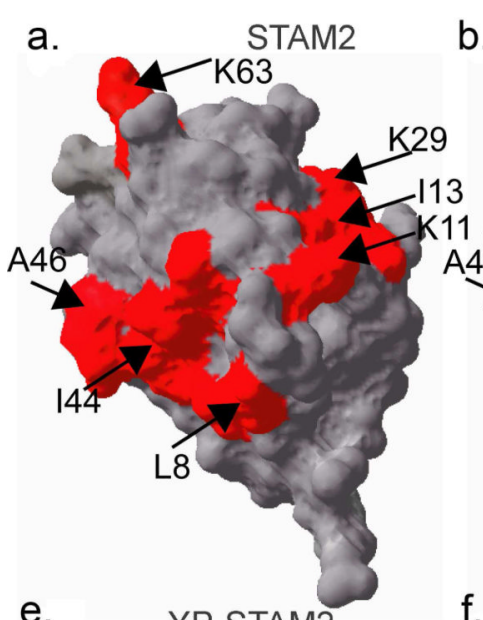

e. YP-STAM2

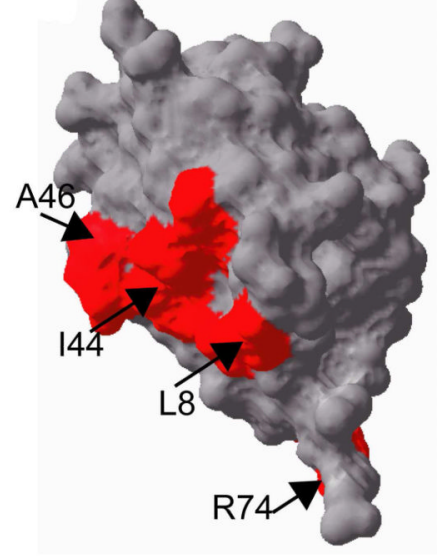

b.

Hrs

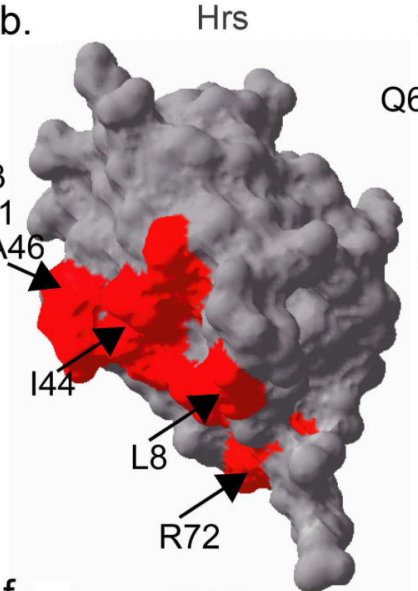

f.

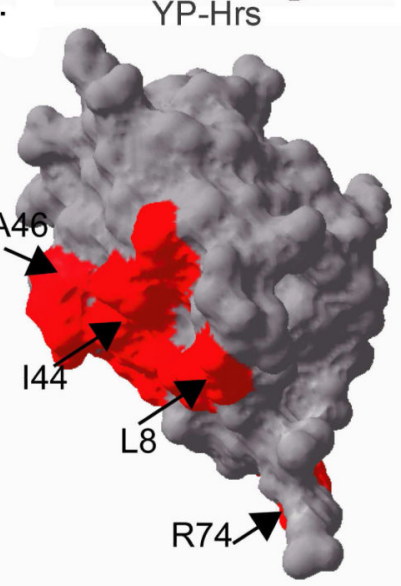

C.<smiles>[13CH3][AsH2][AsH2]</smiles>

g.

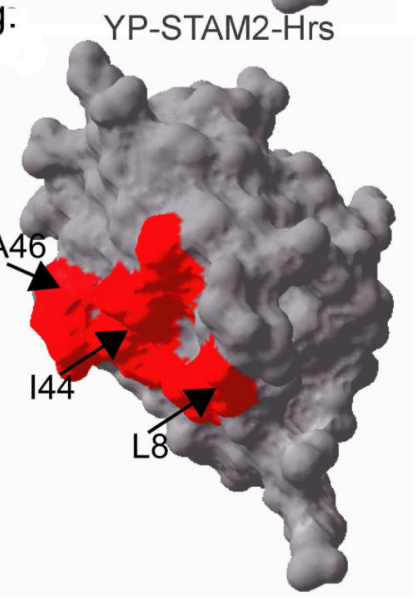

Figure 5.

Interaction surface maps of ubiquitin-ligand complexes. Interaction surface of ubiquitin mapped onto the three-dimensional structure of ubiquitin (PDB code 1D3Z). Individual residues exhibiting either a chemical shift change $>0.05 \mathrm{ppm}$ or significant differential broadening are indicated in white. All perturbed residues lie on the ubiquitin surface and, therefore, reflect changes in the interaction surface of the molecule rather than changes in tertiary or quaternary structure. (a) STAM2-Ubq interaction; (b) Hrs-Ubq interaction; (c) STAM2-Hrs-Ubq interaction; (d) phosphorylated STAM2-Ubq interaction (YP-STAM2); (e) phosphorylated Hrs-Ubq interaction (YP-Hrs); (f) phosphorylated STAM2-Hrs-Ubq interaction (YP-STAM2-Hrs). Ubiquitin ligands are indicated in each panel. Reproduced from Burz and Shekhtman [81] 
a.

in vitro

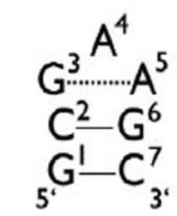

f.

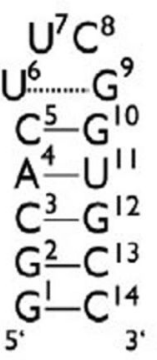

in cell

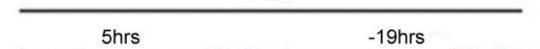

$-19 \mathrm{hrs}$

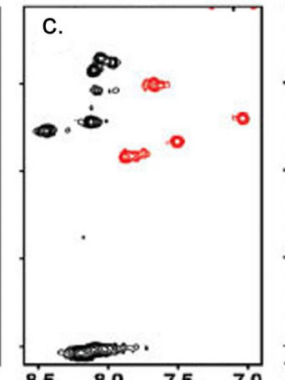

d.

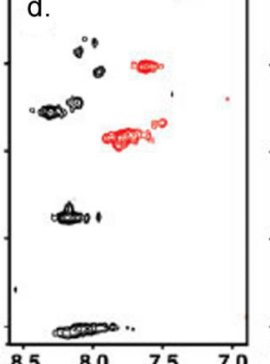

oocyte lysate
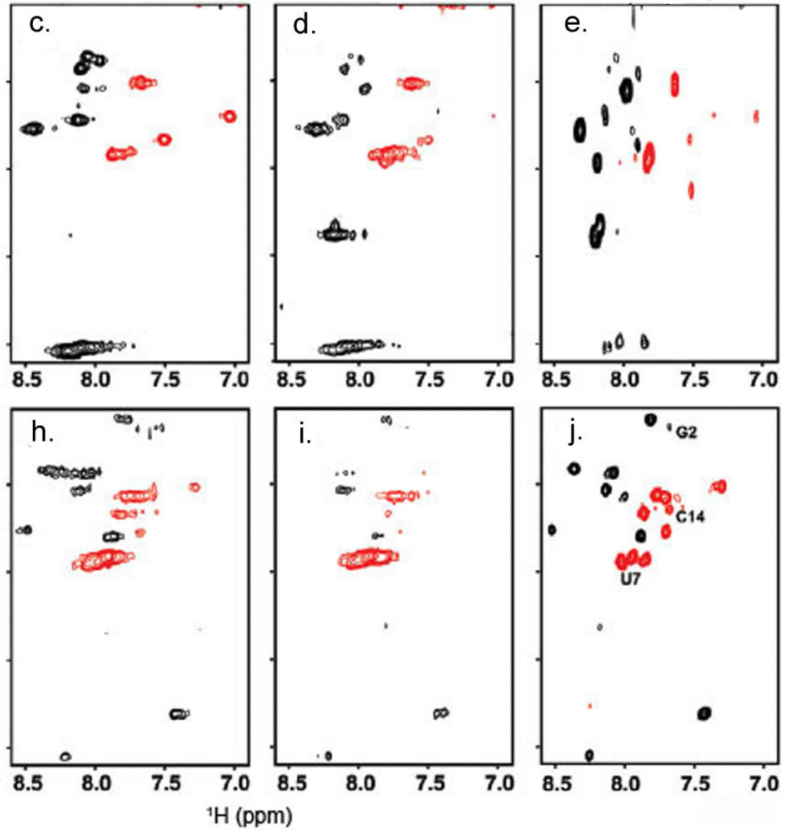

Figure 6.

In-cell $\left[{ }^{1} \mathrm{H}-{ }^{13} \mathrm{C}\right]-\mathrm{CT}$-TROSY-HSQC spectra of the aromatic regions of ${ }^{13} \mathrm{C} /{ }^{15} \mathrm{~N}$-labeled $\mathrm{d}$ (GCGAAGC) and r(GGCACUUCGGUGCC) hairpins. (a) and (f) Schematic representations of secondary structures for d(GCGAAGC) and r(GGCACUUCGGUGCC), respectively. (b) and (G) In vitro spectra of d(GCGAAGC) and r(GGCACUUCGGUGCC). (c) and (d) In-cell NMR spectra of d(GCGAAGC) recorded approximately 5 and $19 \mathrm{~h}$ after microinjection of the $X$. laevis oocytes. (h) and (i) In-cell NMR spectra of $\mathrm{r}$ (GGCACUUCGGUGCC) recorded approximately 5 and $19 \mathrm{~h}$ after microinjection of the $X$. laevis oocytes. (e) and (j) In vitro spectra of d(GCGAAGC) and r(GGCACUUCGGUGCC) in cleared oocyte lysates. The signals in black (positive) and red (negative) correspond to purines and to pyrimidines, respectively. The difference between the signs of the purine and the pyrimidine peaks is due to the constant-time mode of the experiment. NMR spectra were acquired at $291 \mathrm{~K}$. Reproduced from Hansel et al [85]. 